Issued by Sandia National Laboratories, operated for the United States Department of Energy by Sandia Corporation.

NOTICE: This report was prepared as an account of work sponsored by an agency of the United States Government. Neither the United States Government, nor any agency thereof, nor any of their employees, nor any of their contractors, subcontractors, or their employees, make any warranty, express or implied, or assume any legal liability or responsibility for the accuracy, completeness, or usefuiness of any information, apparatus, product, or process disclosed, or represent that its use would not infringe privately owned rights. Reference herein to any specific commercial product, process, or service by trade name, trademark, manufacturer, or otherwise, does not necessarily constitute or imply its endorsement, recommendation, or favoring by the United States Government, any agency thereof, or any of their contractors or subcontractors. The views and opinions expressed herein do not necessarily state or reflect those of the United States Government, any agency thereof, or any of their contractors.

Printed in the United States of America. This report has been reproduced directly from the best available copy.

Available to DOE and DOE contractors from Office of Scientific and Technical Information P.O. Box 62

Oak Ridge, TN 37831

Prices available from (703) 605-6000

Web site: http://www.ntis.gov/ordering.htm

Available to the public from

National Technical Information Service

U.S. Department of Commerce

5285 Port Royal Rd

Springfield, VA 22161

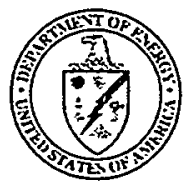




\section{DISCLAIMER}

Portions of this document may be illegible in electronic image products. Images are produced from the best available original document. 
SAND99-3173

Unlimited Release

Printed January 2000

\title{
Ballistic Missile Silo Door Monitoring Analysis
}

\author{
Michael W. Edenburn and Lawrence C. Trost \\ Arms Control Studies Department \\ Nuclear Weapons Program Integration and Studies Center \\ Sandia National Laboratories \\ P.O. Box 5800 \\ Albuquerque, NM 87185-0425
}

\begin{abstract}
This paper compares the cost and effectiveness of several potential options that may be used to monitor silo-based ballistic missiles. Silo door monitoring can be used to verify that warheads removed to deactivate or download silo-based ballistic missiles have not been replaced. A precedent for monitoring warhead replacement using reentry vehicle on site inspections (RVOSIs) and using satellites has been established by START-I and START-II. However, other monitoring options have the potential to be less expensive and more effective. Three options are the most promising if high verification confidence is desired: random monitoring using door sensors; random monitoring using manned or unmanned aircraft; and continuous remote monitoring using unattended door sensors.
\end{abstract}




\section{Contents}

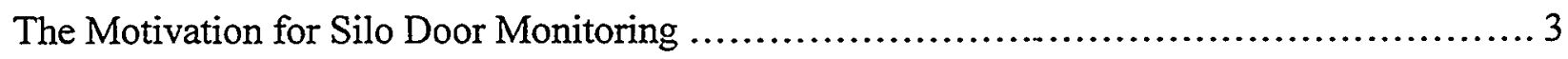

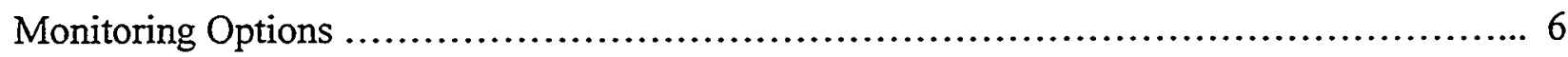

Random Monitoring with Confirmation .......................................... 6

Random Monitoring without Confirmation ........................................ 7

Continuous Monitoring .............................................................. 8

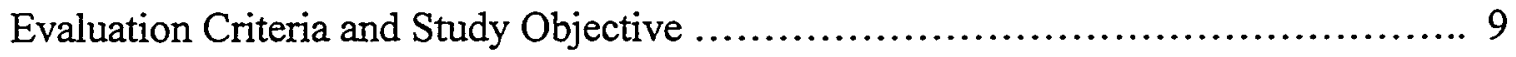

Analysis of Monitoring Options ...................................................... 11

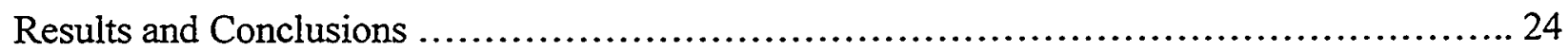

Appendix A. Missile upload detection probabilities for random monitoring with

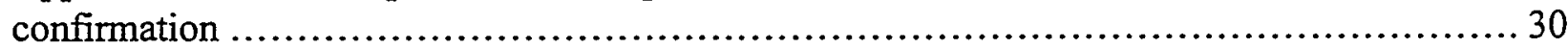

Appendix B. Missile upload detection probabilities for random monitoring without

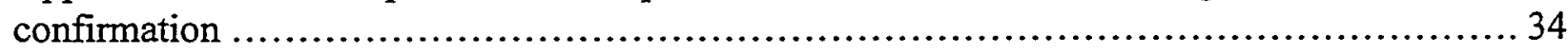

Appendix C. General assumptions about monitoring manpower and cost estimates ............ 38

Appendix D. Manpower and cost estimates for random monitoring with confirmation ........ 40

Appendix E. Manpower and cost estimates for random monitoring without confirmation ....... 48

Appendix F. Manpower and cost estimates for continuous monitoring ..................... 56

Appendix G. Design Features for a Monitoring System Using Over-Flights with

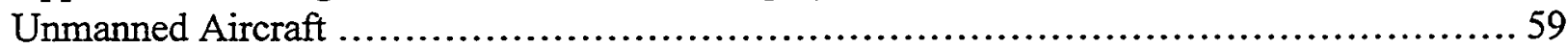

Appendix H. Design Features for a Monitoring System Using Random Monitoring with

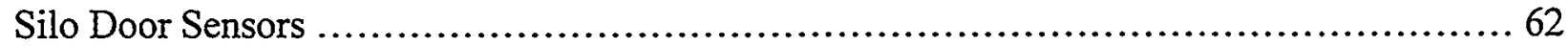

Appendix I. Design Features for a Continuous Remote Monitoring System Using

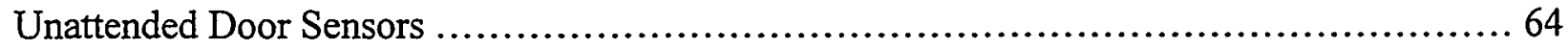

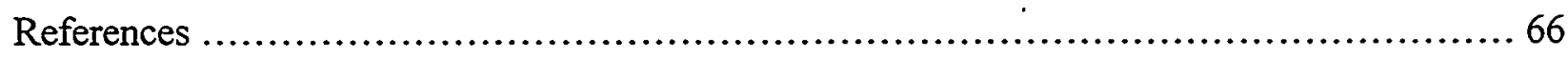




\section{The Motivation for Silo Door Monitoring}

This paper compares the cost and effectiveness of potential monitoring options which could be used as part of a verification regime to confirm that warheads removed to deactivate silo-based ballistic missiles, pursuant to possible future international treaties or agreements, have not been replaced. The monitoring options considered could also be used to verify that downloaded silobased missiles remain downloaded, but this application is not addressed in this paper.

At the 1997 Helsinki Summit, presidents Yeltsin and Clinton agreed that "the Russian Federation and the United States of America shall deactivate, by December 31,2003, all strategic nuclear delivery vehicles which will be eliminated under the Treaty (START-II), by removing their nuclear reentry vehicles or taking other jointly agreed steps." If START-II is ratified, it will require eliminating Peacekeepers, SS-18s, SS-24s, and all but 105 SS-19s.

If missiles are deactivated by removing their warheads, they can be reactivated by replacing their warheads. Since the missiles must be deactivated by December 31, 2003 and eliminated by December 31,2007 , the potential for covertly reactivating the missiles in violation of START-II would exist for four years. Silo door monitoring could be used to detect covert reactivation during this transition period. Table 1 shows the number of silo-based missiles that must be deactivated, and the associated numbers of warheads, if START-II is ratified (Jane's, 1998 and Reporter, 1998). The table assumes that Russia will possess 168 SS-19s upon completing the terms of START-I, and that they will retain the 105 SS-19s allowed by START-II. On January 1,2004 , the total upload capability for deactivated silo-based missiles will be 2518 warheads--a significant fraction of the 3000 to 3500 accountable warheads allowed by START-II for each country--if the treaty is ratified and the Helsinki agreement is put into effect. Thus, upload capability for silo-based missiles that have been deactivated will be a significant fraction of total ballistic missile force warheads. Because there will be a large number of warheads associated with deactivation, it may be desirable to have a verification regime that gives high confidence in discovering uploads before a large fraction of the deactivated force can be uploaded.

START-II calls for the same verification regime as START-I, which includes ten reentry vehicle on-site inspections (RV-OSIs) each year and the use of satellites (NTM). It is not likely that the basic START-II verification regime will change; however, the terms for deactivation have not been negotiated; and, it is possible that additional verification measures for deactivated missiles can be negotiated as an integral part of deactivation negotiations. The obvious candidate options for additional monitoring associated with deactivation are RV-OSIs and satellites since a precedent for them was set by START-I and START-II. 
Table 1. Potential Warhead Uploading on Silo-Based Ballistic Missiles to be Deactivated Under START-II

\begin{tabular}{|l|r|r|}
\hline $\begin{array}{c}\text { Silo-Based } \\
\text { Missiles to be } \\
\text { Eliminated Under } \\
\text { START-II }\end{array}$ & $\begin{array}{c}\text { Numbers of } \\
\text { Missiles to be } \\
\text { Deactivated }\end{array}$ & $\begin{array}{c}\text { Warhead Upload } \\
\text { Potential }\end{array}$ \\
\hline & & 500 \\
\hline U.S. & 50 & \\
\hline Peacekeeper & & 1540 \\
\hline & & 378 \\
\hline Russian & 154 & 100 \\
\hline SS-18 & 63 & 2018 \\
\hline SS-19 & 10 & \\
\hline SS-24 & 227 & \\
\hline Total Russian & & \\
\hline & & \\
\hline Total & & \\
\hline
\end{tabular}

RV-OSIs and satellite imaging give very different verification results. At each inspection, an RV-OSI will confirm that a missile has or has not been covertly uploaded. If all missiles have been uploaded, an RV-OSI should discover uploading at the next inspection. In contrast, satellite imaging cannot confirm that a missile has or has not been uploaded because it cannot see into a closed silo: it must catch uploading in the act. The confidence one has in discovering an uploading process depends in part on whether or not an inspection is able to confirm the absence of uploads. It also depends on the rate at which missiles are uploaded and on the rate at which inspections are conducted. In Appendix A we estimate the probability of discovering uploading if an inspection can confirm the absence of uploads, and in Appendix B we estimate the probability of discovering uploading if an inspection cannot confirm the absence of uploading in which case uploading must be caught in the act. Both appendices consider a 154 missile, deactivated SS-18 force and assume that an SS-18 can be uploaded in 12 hours.

As an example, if $10 \mathrm{RV}$-OSIs are conducted each year, the probability that uploading will be discovered before all missiles are uploaded is a little less than $25 \%$ (see Figure 3, with confirmation). This assumes that the Russians can upload 8 missiles each day and if it takes them 12 hours to upload each missile. Thus, ten RV-OSIs do not give high confidence in discovering uploading before a large fraction of the force is uploaded; however, they guarantee that uploading will be discovered on the next inspection after the entire force has been uploaded. Under the same assumptions, roughly $2000 \mathrm{RV}$-OSIs are needed to get a $90 \%$ discovery probability before 30 missiles ( $20 \%$ of the SS- 18 force) are uploaded. Two-thousand annual RVOSIs would cost roughly $\$ 20$ million (see Figure 4). 
According to Figure 3 (without confirmation), we need roughly 9000 annual random satellite images to reach a $90 \%$ probability of discovering an upload before 30 missiles are uploaded. For 9000 images, the total annual cost will be roughly $\$ 46$ million (see Figure 10). The combination of 9000 random satellite images and 10 RV-OSIs each year would give good confidence in discovering uploading before 30 missiles are uploaded and would guarantee that uploading will be discovered shortly after all missiles have been uploaded. The combination would cost in excess of $\$ 40$ million each year.

Other monitoring options have the potential to provide higher detection confidence at lower cost. In the remainder of this report, we will compare RV-OSIs and satellite monitoring, with other silo door monitoring options. 


\section{Monitoring Options}

While the overall objective of silo door monitoring is to verify that missiles which have been deactivated by removing their warheads have not been reactivated, different silo door monitoring options will approach the objective in different ways and will obtain different types of results. The differences will become clear as we discuss the different monitoring options and divide them into three classes. Within each monitoring class, the different monitoring options have similar, but not identical, features. The following list shows the three classes of monitoring options.

\section{Random Monitoring with Confirmation \\ Random monitoring with warhead counting inspections \\ Random monitoring with warhead counting using aircraft \\ Random monitoring using door sensors \\ Random Monitoring without Confirmation \\ Random monitoring using inspection teams \\ Random monitoring using over-flights with manned or unmanned aircraft \\ Random monitoring using satellites}

\section{Continuous Monitoring}

Continuous monitoring using inspection teams

Continuous monitoring using unmanned aircraft

Continuous remote monitoring using unattended door sensors

\section{Random Monitoring With Confirmation}

Confirmation means that the silo doors are opened and missiles are inspected to confirm that warheads have not been replaced, or alternately, sensor packages applied to each silo door are checked by inspectors to confirm that the silo doors have not been opened. This class of monitoring option will give very high confidence that warhead replacement will eventually be discovered even though uploading may not be detected as it occurs. The confidence in discovering an uploaded missile depends on the number of missiles uploaded, the frequency of monitoring, and the rate at which warheads are replaced. The relationship between these parameters is quantified in Appendix A and in Figure 3 for a 154 missile SS-18 force. The analysis in Appendix A assumes that monitoring is performed at random times. Randomness slightly improves detection probability compared to periodic monitoring when the absence of warheads is confirmed but is less important than for inspections that do not confirm the absence of warheads. The advantage of this class of options is that it practically guarantees that uploading will be discovered during the first inspection after all missiles have been uploaded. A potential disadvantage of this monitoring option class is that it requires greater cooperation by the country being inspected than do other classes since inspectors must gain access to the site and to the silo's interior. If site access or silo door opening is delayed, inspection frequency may 
decrease and the time required to discover uploaded missiles may increase. Appendix D covers random monitoring with confirmation options in more detail.

Random Monitoring With Warhead Counting Inspections--This option would use an inspection team to randomly inspect sites. The inspection would require that silo doors be opened and that the warheads on each missile be counted to confirm that missiles remain downloaded. It requires cooperation by the inspected party to open silo doors and remove missile shrouds in a timely manner and allow sufficient time for inspection. This monitoring option is very intrusive and relatively expensive; however, there is a precedent for this type of monitoring under START-I and START-II, namely reentry vehicle on-site inspections (RV-OSIs).

Random Monitoring with Warhead Counting Using Aircraft--This option would use an aircraft equipped with visible light and infrared cameras to count warheads in opened silos. Host country ground-teams would be required to open and close silo doors to permit photographic imaging of the silo's interior. This option might only be effective for monitoring deactivated ICBMs whose warheads and shrouds have been completely removed. If shrouds were left in place, this option would not be effective. Aircraft base location and weather are also issues for this type of monitoring, and the host country may have safety or security concerns about an aircraft flying directly over open silos.

Random Monitoring Using Door Sensors--This option would use an inspection team to randomly inspect sites. Instead of opening the silo door to count warheads, the inspector interrogates a sensor package applied to the silo door to confirm that the silo door has not been opened. The sensor package would use technical devices such as motion sensors, inclinometers, magnetic switches, or encoded break beams that continuously monitor silo door status, and it would include tamper protection. This type of inspection does not require that silo doors be opened unless the sensor has been disturbed. Replacing warheads requires opening the silo door; thus, confirming that the door has not been opened is equivalent to confirming that warheads have not been replaced. The necessity of finding a good location for sensors and resistance to countermeasures will be the main issues for this type of monitoring. This option is described in more detail in Appendix $\mathrm{H}$.

\section{Random Monitoring Without Confirmation}

With this class of monitoring options, silo doors are monitored randomly to see if they are closed, but they are not opened to confirm that warheads have not been replaced, and sensors are not used to confirm that doors have remained closed. This class of monitoring options relies on random and frequent inspections to achieve a high probability that warhead replacement will be caught in the act. Detecting an open silo door or detecting warhead replacement equipment around the silo door would constitute catching uploading in the act. We assume that 12 hours are required for uploading an SS-18, thus there is a 12 hour period over which SS-18 uploading can be caught in the act. The confidence in detecting an upload depends on the number of missiles uploaded and on the frequency of monitoring. The relationship between these parameters is 
quantified in Appendix B and in Figure 3 for a 154 missile SS-18 force. The advantages of this monitoring class are that inspections can be accomplished much more quickly and cooperation from the inspected country is less extensive than for the monitoring-with-confirmation case. It is not required that silo doors be opened and it may be possible to confirm that silo doors are closed without entering a restricted site. A disadvantage is that discovery of uploaded missiles is not assured. If warheads are replaced without detection, they will remain undetected unless the door is opened and warheads are counted. This class of monitoring options is discussed in greater detail in Appendix E.

Random Monitoring using Inspection Teams--This option would use inspection teams to randomly inspect sites. It would not open doors nor use door sensors, relying instead on the frequency of inspection to achieve a statistical probability that warhead replacement would be caught in the act by observing an open silo door or warhead loading equipment around the silo. The primary issue for this type of monitoring will be the large number of inspections along with associated protocols required.

Random Monitoring using Over-flights with Manned or Unmanned Aircraft--This option would use manned or unmanned aircraft over-flights with visible light, infrared, and possibly synthetic aperture radar imaging to monitor silo doors and is similar in concept to satellite monitoring although different technologies are used. Since silo doors remain closed, uploading must be caught in the act. Aircraft base location and weather are issues for this type of monitoring. An additional issue will be the large number of over-flights and the notification and permission protocols required. See Appendix $G$ for more details.

Random Monitoring using Satellites--This option would use current or enhanced NTM subject to the availability of NTM assets or commercial satellites employing visible light, infrared, and possibly synthetic aperture radar imaging. Satellites would view silos (perhaps several at a time depending on the satellite's field of view) to determine if silo doors are open or if uploading equipment is present, which may imply that warheads are being replaced. Satellite inspections are not truly random since the host country can predict when a satellite will be within view of a silo. Because of this, a satellite must come into view of each silo at least every 12 hours, our assumed time required for uploading. The satellite need not photograph each silo every 12 hours, but it must have the capability to do so; otherwise, the host country could plan an undetectable upload schedule based on the satellite constellation's schedule. One might conjecture that when a satellite is coming into view, the host country could interrupt an ongoing uploading process, move equipment, close the silo door, and resume operations when the satellite is no longer in view; however, we believe this would not be practical. Near-random monitoring may be achieved using several satellites and tasking them at random to photograph silos. Presumably, the satellite constellation would have other tasks in addition to silo monitoring. The main issue associated with satellite monitoring without confirmation will be cost. We did not consider using satellites for monitoring with confirmation, requiring that silo doors be opened as satellites pass over silos, because we cannot address the adequacy of their imaging resolution to count warheads and identify evasion attempts to fool image analysts. 


\section{Continuous Monitoring}

For this class of monitoring options, silo doors are continuously monitored to insure that doors have not been opened and warheads replaced. This class of monitoring options has the advantage that it will give high confidence that warheads have not been replaced. Its disadvantage is that it requires a fairly intensive and possibly intrusive monitoring regime. By continuous monitoring, we do not mean that each silo is watched continuously. For our purposes, continuous monitoring means that silos are inspected more often than the shortest time required to replace a missile's warheads, which is assumed to be 12 hours. Continuous monitoring options are discussed in greater detail in Appendix F.

Continuous Monitoring using Inspection Teams--This option would use inspection teams at each missile field at all times to monitor missile silos. The interval between inspections at each silo must be shorter than the time required to upload a missile. The primary issues will be the cost of monitoring and the intrusiveness of having a large number of inspectors in the host country at all times.

Continuous Monitoring Using Unmanned Aircraft--This option would use unmanned-aircraft crews stationed at or near missile fields at all times and unmanned aircraft to perform full time missile field monitoring. Unmanned aircraft would use visible light and infrared cameras to photograph silo areas and confirm that silo doors remain closed and that equipment used to upload warheads is not in the vicinity of a silo. Each silo must be monitored more frequently than the time required to upload a missile. Aircraft base location, weather, the large number of over-flights, and the notification and permission protocols required will be the main issues for this option.

Continuous Remote Monitoring Using Unattended Sensors--This option would use technical devices such as motion sensors, inclinometers, magnetic switches, encoded break beams, or cameras which continuously monitor silo door status. The monitoring system would include tamper protection, signal encoding, and authenticated telecommunication, probably via satellite. It may also include more than one technology to improve the detection probability and decrease the false alarm rate. The main issues associated with this type of monitoring are technology maturity, resistance to countermeasures, and past precedents. See Appendix I for more details.

\section{Evaluation Criteria and Study Objective}

Several criteria should be considered when evaluating ICBM silo door monitoring options:

Effectiveness (probability of detection, expected detection time)

Life Cycle Cost (installation costs, operating costs)

System Errors (probability of a false negative, false alarm rate),

Robustness (failure rates, resistance to environment, resistance to countermeasures),

Acceptability (intrusiveness, security issues, personnel requirements). 
The objective of this analysis is to evaluate ICBM silo door monitoring options based on the first two criteria, effectiveness and life-cycle cost. We will consider the last three criteria, but not in depth and not quantitatively.

Every monitoring option will require an initial confirmation that the appropriate number of warheads has been removed. The cost of this initial confirmation is not included in the cost for the different options, since it is a common cost to every option. 


\section{Analysis of Monitoring Options}

We directed this study at a specific type of missile, the SS-18. Our results for the SS-18 can be extended later to other missile types; however, we believe that we will be able to draw some general conclusions even though we focus on a specific missile.

Assumptions about SS-18s:

Deployed in 4 fields--Kartaly, Domborovsky, Uzhur, and Aleysk (see Figure 1)

Domborovsky and Kartaly are roughly $300 \mathrm{~km}$ apart

Aleysk and Uzhur are roughly $500 \mathrm{~km}$ apart

Domborovsky and Aleysk are roughly $1600 \mathrm{~km}$ apart

The total number of missiles is 154

Silos are $6 \mathrm{~km}$ apart (rough average)

Replacing the warheads on a missile requires 12 hours (a rough estimate)

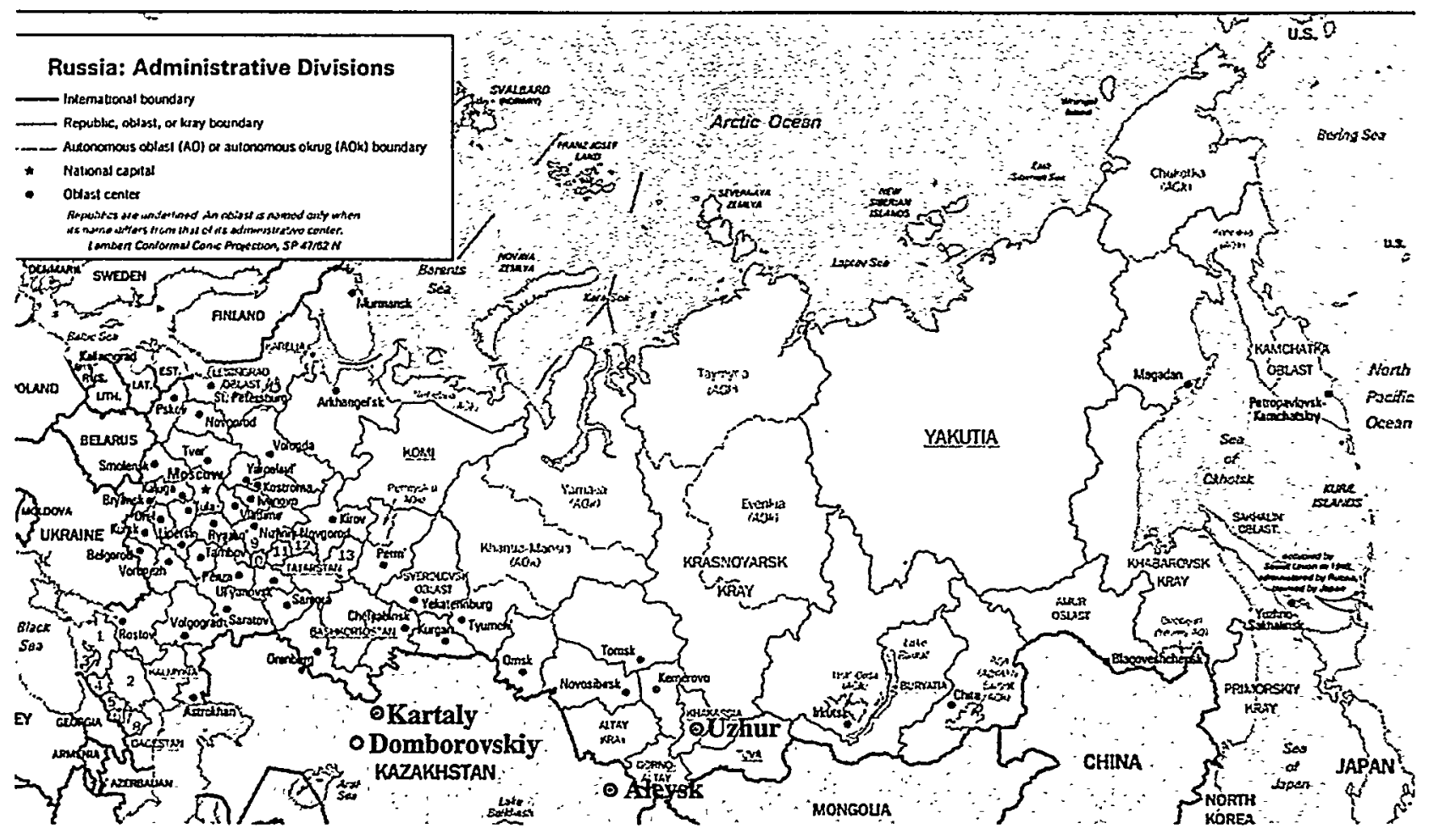

Figure 1. Russian SS-18 Bases 
The door of an SS-18 silo is shown in Figure 2

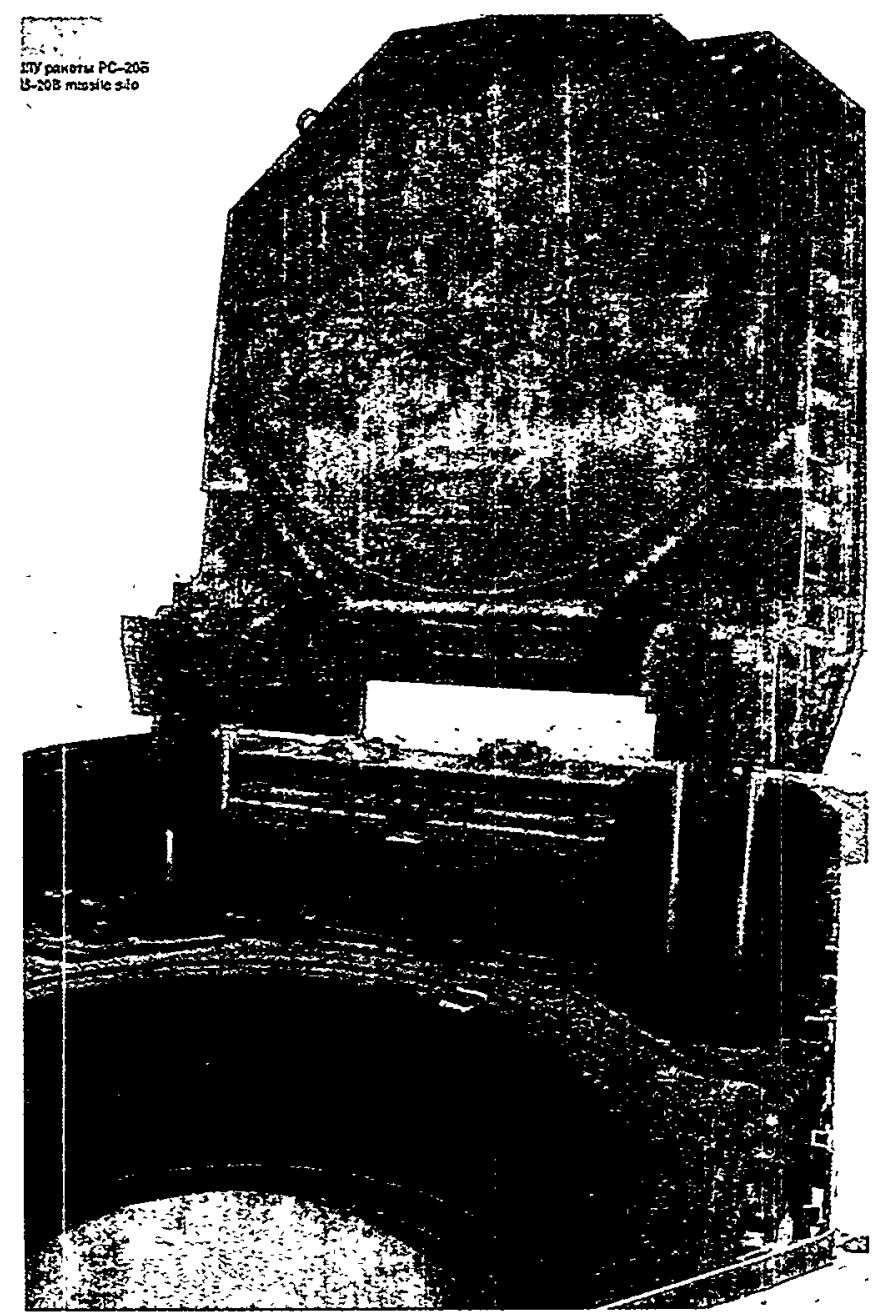

Figure 2. SS-18 Silo Door

We will use upload detection probability as the measure of a monitoring option's effectiveness, although there are other issues that must also be considered. The detection probability for a monitoring option depends on the class of monitoring option, the number of missiles uploaded, the rate at which missiles are uploaded, the time it takes to upload a missile, and the frequency of monitoring. The probability of detecting SS-18 reactivation (warhead uploading), is detailed in Appendices A (for monitoring with confirmation) and B (for monitoring without confirmation) and summarized in Figure 3 for the case where eight missiles can be uploaded each day. The blue lines in Figure 3 represent the probability of detecting reactivation for monitoring with confirmation. The red lines represent the probability of detecting reactivation for monitoring without confirmation. Probability increases as the inspection rate increases and as the number of missiles uploaded increases. The dashed horizontal lines in Figure 3 are at 30 and 154 missiles uploaded ( $20 \%$ and $100 \%$ of the fissile force respectively), examples that will be referred to later. 


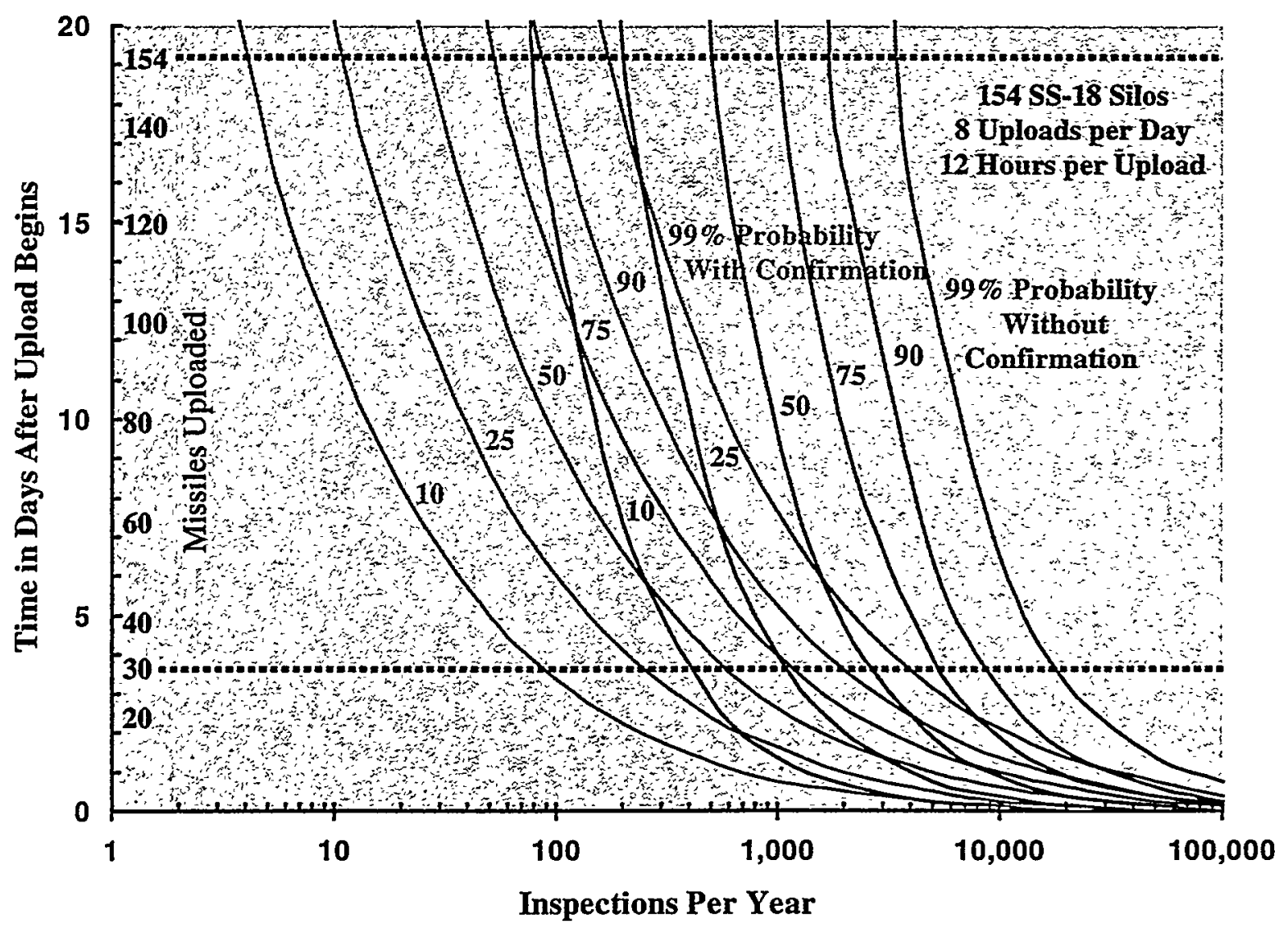

\section{Figure 3. Probability of Detecting Uploads Before a Specified Number of Missiles Have Been Uploaded}

Since we assume that 8 missiles are uploaded each day, the number of missiles uploaded is associated with a specific time in days on the $\mathrm{Y}$-axis of this figure. Notice that the red and blue lines continue beyond the point at which time all 154 missiles have been uploaded. The red lines (monitoring without confirmation) become vertical at this point. Additional inspections will not increase detection probability since uploading is complete, and monitoring without confirmation can no longer discover uploading. The blue lines are not vertical after all missiles have been uploaded since the next inspection is practically assured of discovering an uploaded missile. The time it takes to make that discovery is random, but it depends on the frequency of inspections.

To estimate costs for the various monitoring options considered, we adopted several cost assumptions that we applied as uniformly as possible across the different monitoring options. We did this so that comparisons among options are as unbiased as possible. These general cost assumptions are listed in Appendix C.

We will now examine the individual monitoring options in the order in which they were presented earlier in this report. It may be advantageous to combine monitoring options, but combinations are not considered in this report. 


\section{Random Monitoring with Warhead Counting Inspections}

The Start I protocol for reentry vehicle inspections uses a ten man team plus escorts and requires removing a missile's reentry vehicle section, moving it to a nearby assembly facility, shrouding the reentry vehicles with a blanket, and counting the peaks that the RVs produce in the blanket. This warhead counting procedure takes roughly 12 hours. The complete inspection requires roughly 10 days: 2 days for travel, 4 days in country, and 4 days for follow-up briefings (Leahy, 1998). According to Leahy, if missiles are loaded with a single warhead or no warheads, inspections may require less time (possibly half a day) and fewer (7 to 8 ) inspectors.

For post-START-II inspections, if warheads are removed to deactivate missiles scheduled for elimination, these missiles will have no warheads and smaller inspection teams may be possible. For a single, warhead counting inspection (one silo), we assume that an inspection team would consist of 7 inspectors, 4 escorts, and support personnel. In Table D1, we estimate that a single inspection would cost $\$ 142,000$ using the uniform cost assumptions set out in Appendix C. Our $\$ 142,000$ cost estimate for an 11 man team ( 7 inspectors +4 escorts) is consistent with cost figures given to us by OSIA (Skipper, 1998).

We assume that a full time inspection team which counts warheads would consist of 7 inspectors and 4 escorts, and costs would include travel, living expenses, and support personnel. We estimate that such a team can conduct 639 inspections each year (see Appendix D), and we estimate its cost to be $\$ 6.1 \mathrm{M} / \mathrm{Yr}$ in Table D2. This cost is significantly lower per inspection than the $\$ 142,000$ estimated for a single inspection because a full time team would spend significantly less time in travel and preparation for each inspection than a team which conducts a single inspection. Figure 4 shows annual inspection cost as a function of the number of inspections per year taken from Table D3. Between 12 inspections, which we assume are monthly individual inspections, and 660 inspections per year, we fit a straight line. This line may not be accurate for some specific cases but gives the proper general trend. 


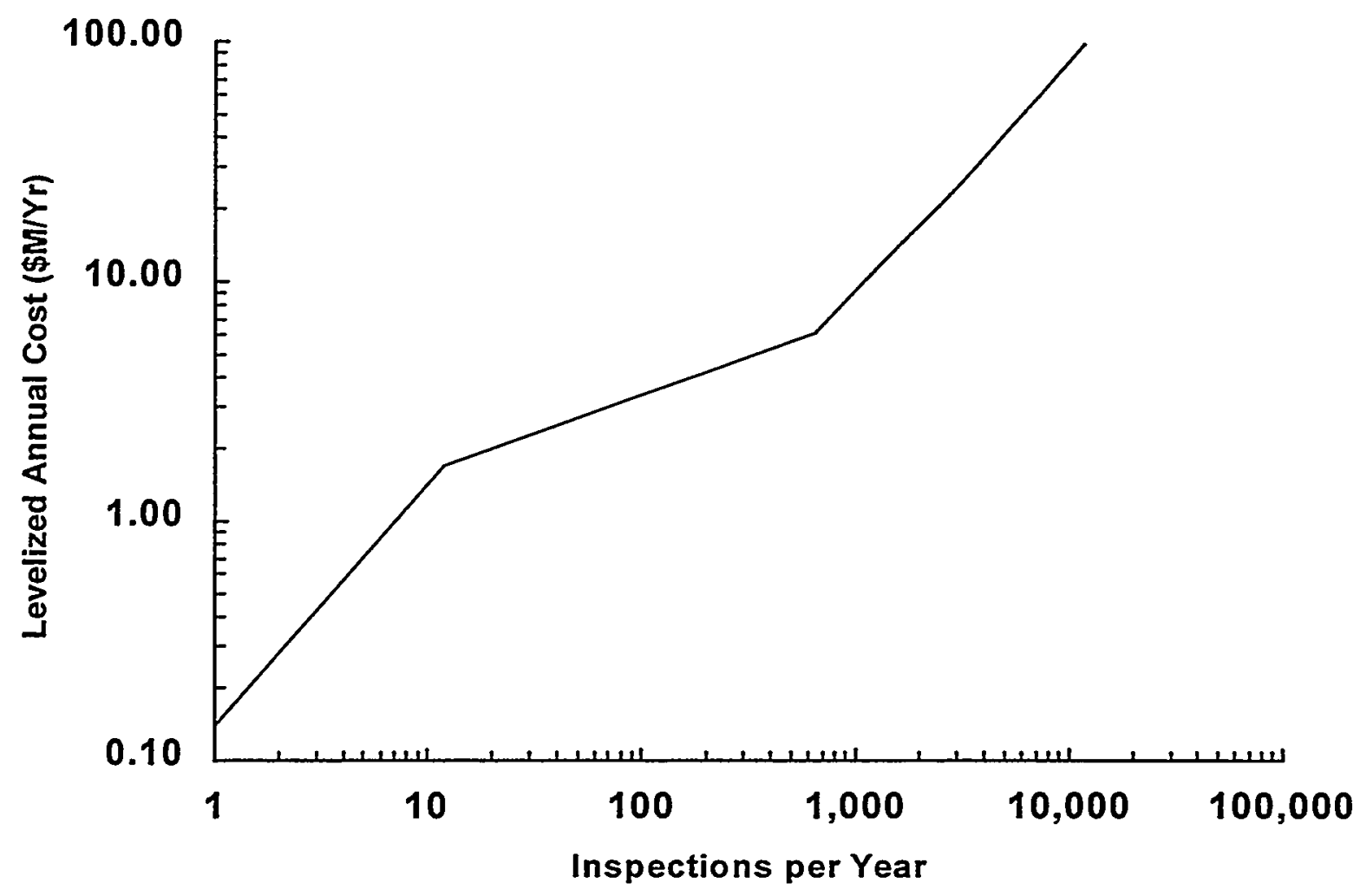

Figure 4. Silo Door Monitoring Cost Random Monitoring with Warhead Counting Inspections 


\section{Random Monitoring with Warhead Counting using Aircraft}

Instead of using an inspection team on the ground, this option uses an aircraft with visible light and infrared cameras to photograph open silos. The images would be analyzed to confirm that the missile holds the proper number of warheads. We believe that photographic resolution is adequate to allow warhead counting, particularly since there will be no warheads, and assure that measures are not being used to fool analysts (Wu, 1998). This option can potentially be faster than using an inspection team on the ground; however, several host country ground crews would be required to open and close silo doors.

We assume that an inspection team consists of an aircraft and 3 inspectors: a pilot, a copilot, and an equipment operator. In addition, a one-man escort will probably be required and one or more 3-man ground crews. Our estimate of costs for the aircraft (amortized over 10 years), inspection team, escorts, and ground crews are shown in Tables D4 through D6. We assume that an aircraft can cover 2 fields ( 77 silos) each day and that a ground crew can open and close 4 silos each day. Since the aircraft can cover many more silos than a ground crew can open, several ground crews may be necessary. The relation between annual inspection cost and the number of silo inspections is summarized in Table D7 and in Figure 5.

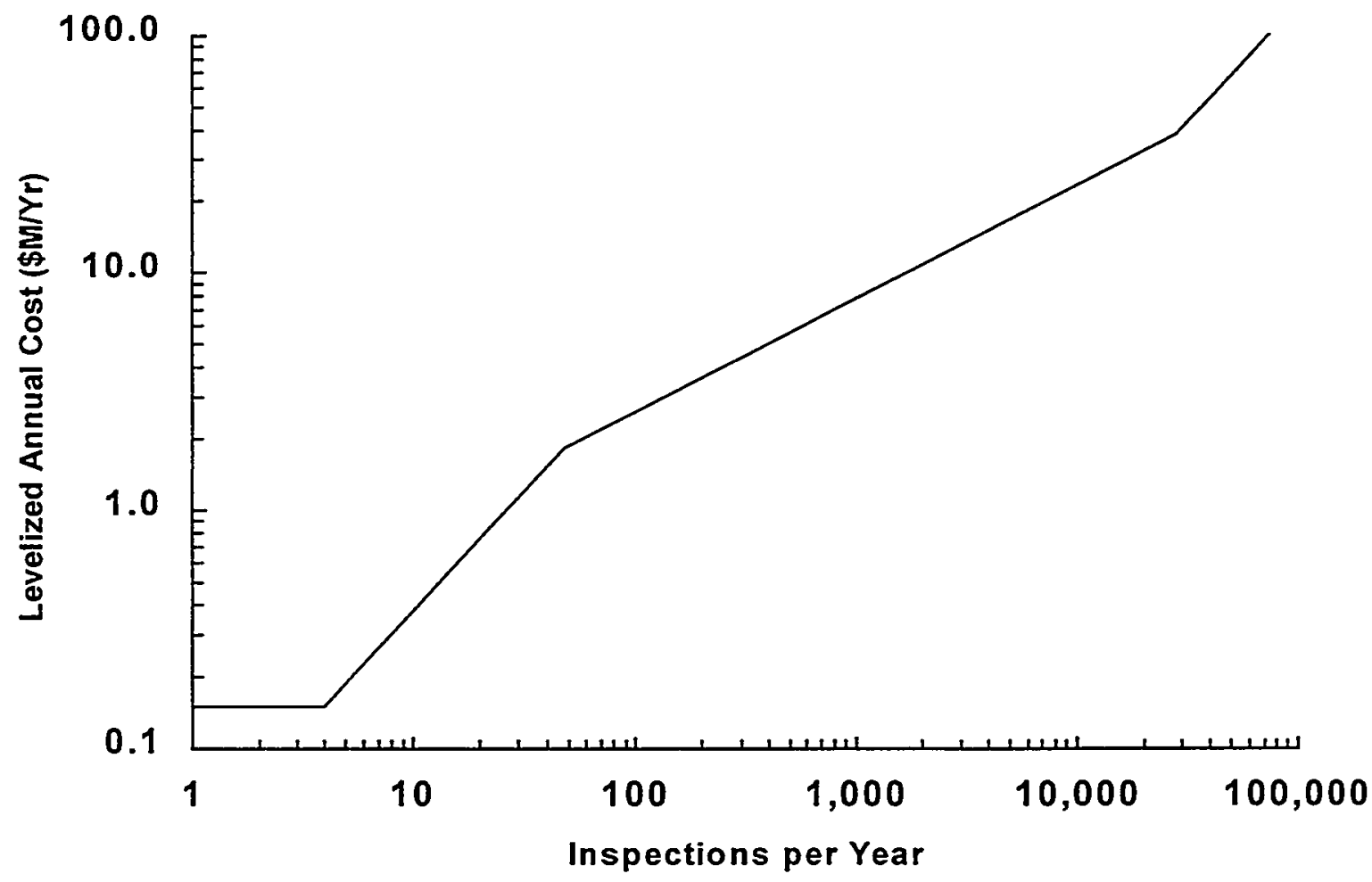

Figure 5. Silo Door Monitoring Cost Random Monitoring with Warhead Counting using Aircraft 


\section{Random Monitoring Using Door Sensors}

For this monitoring option, an inspector interrogates a sensor package placed on the silo door to verify that the door has not been opened. We assume that active sensors with significant antitamper protection will be used. Silo doors are not opened, and warheads are not counted. This option will be much faster and require fewer inspectors than the option that involves open doors with warhead counting.

We assume that the inspection team requires 3 inspectors with 2 escorts since warheads do not have to be counted. Sensor package installation cost is estimated in Table D8. The cost for a single inspection trip that includes 12 silo inspections is estimated in Table D9. The cost of a full time inspection team is estimated in Table D10, and we estimate that it can perform 2342 inspections each year. Cost as a function of the annual number of inspections is shown in Figure 6 and is tabulated in Table D11.

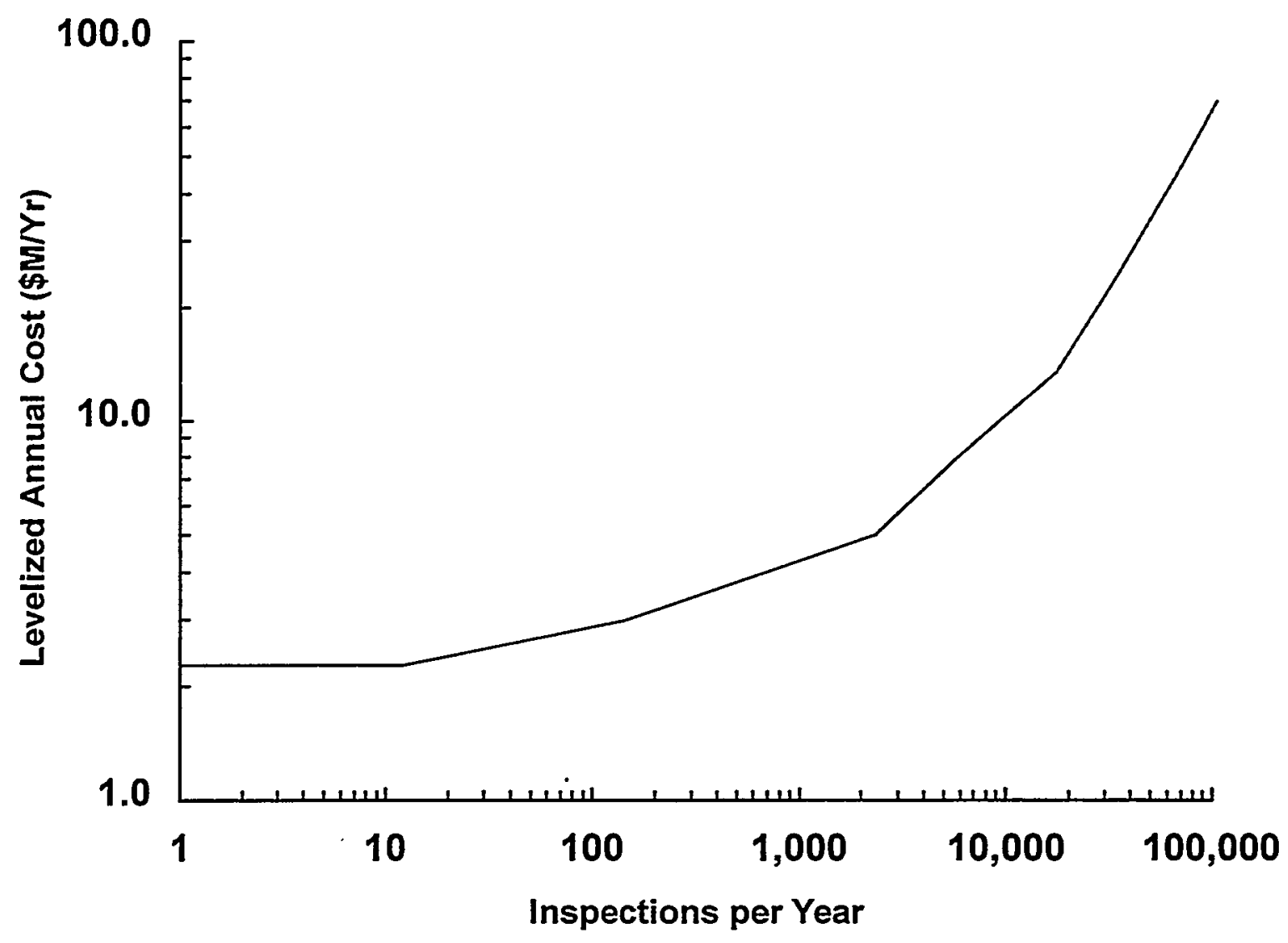

Figure 6. Silo Door Monitoring Cost Random Monitoring Using Door Seals 


\section{Random Monitoring Using Inspection Teams}

In this case, since silo doors remain closed and sensors are not used to confirm that doors have remained closed, monitoring teams must catch uploading in the act. Catching warhead replacement in the act will require an inspection team at each field (four teams), otherwise warheads can be replaced while an inspection team is traveling between fields. These four teams can inspect 35,040 silos each year (see Appendix E). Table E2 shows the number of inspections each year and the cost for 4,8 , and 16 inspection teams. We assume that an inspection team will consist of three inspectors and that the cost of each team is $\$ 2.8 \mathrm{M} / \mathrm{Yr}$ as estimated in Table E1. Figure 7 shows inspection cost as a function of annual number of inspections.

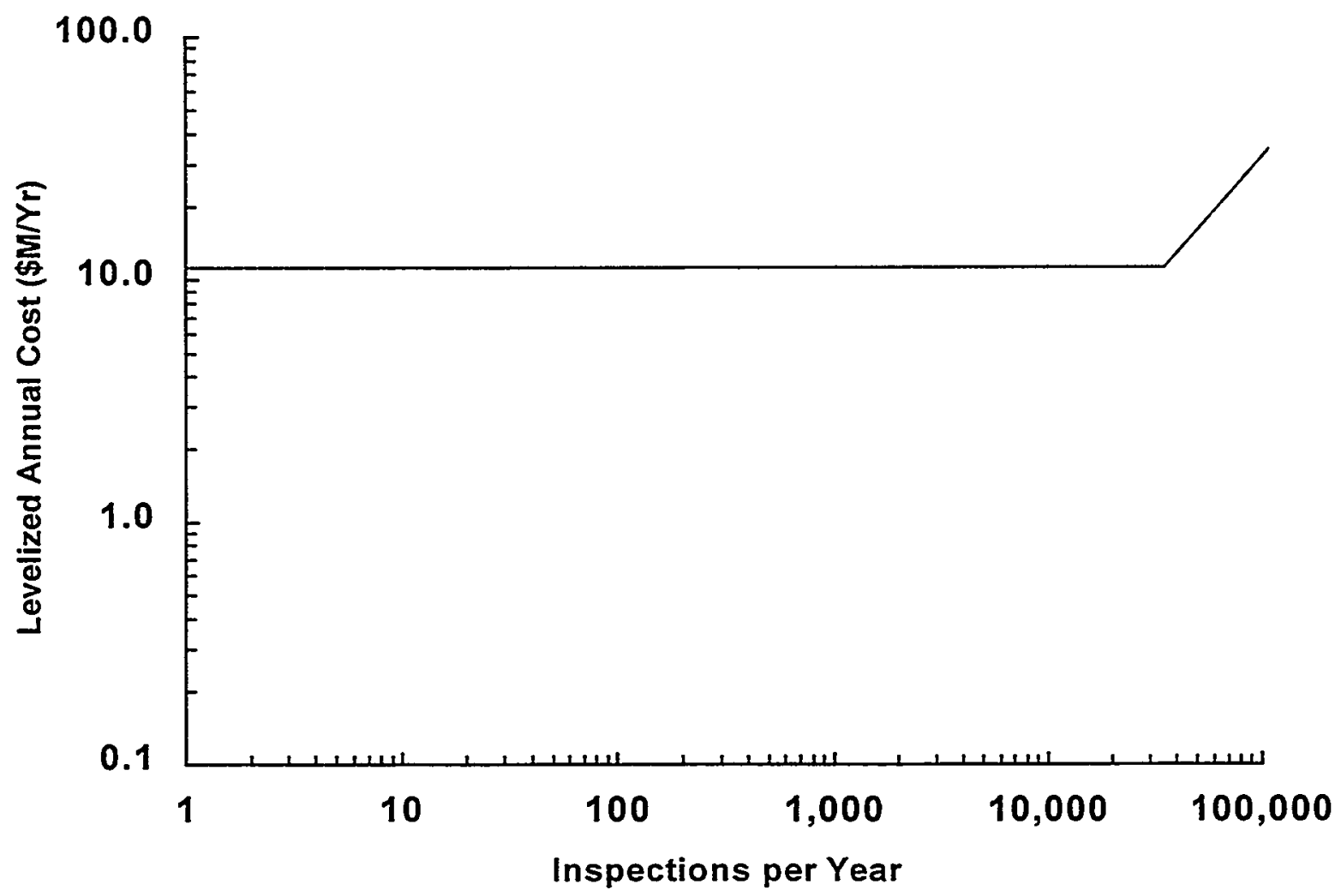

Figure 7. Silo Door Monitoring Cost Random Monitoring with Doors Closed and No Seals 


\section{Random Monitoring Using Over-Flights with Manned Aircraft}

We assume that manned over-flights would use visible light photography and infrared photography to image silo doors and the immediately surrounding area. For this option, we assume that over-flights must catch uploading in the act, that is, during the 12 hour period required to upload a missile.

We assume that an inspection team used to conduct a few inspections each year consists of 2 inspectors who serve as pilots, equipment operators, and imagery interpreters. In addition, we believe that a one-man escort will be required. The cost of an instrumented aircraft (amortized over 10 years) is estimated in Table E3. In Table E4, we estimate that a few (154) manned overflights will cost $\$ 2.6 \mathrm{M}$. Since these over-flights must catch uploading in the act, they must be conducted at random times. That means that an aircraft and team must be on alert at all times; otherwise, the host country could upload when the inspection team is off duty. In Table E5, we estimate that a full time team consisting of 5 inspectors (4 pilots operating in two shifts and an imagery interpreter) will cost $\$ 5.8 \mathrm{M} / \mathrm{Yr}$. We further assume that an aircraft will be assigned to each full-time inspection team. The relation between inspection cost and annual number of inspections is shown in Figure 8, which was generated from Table E6.

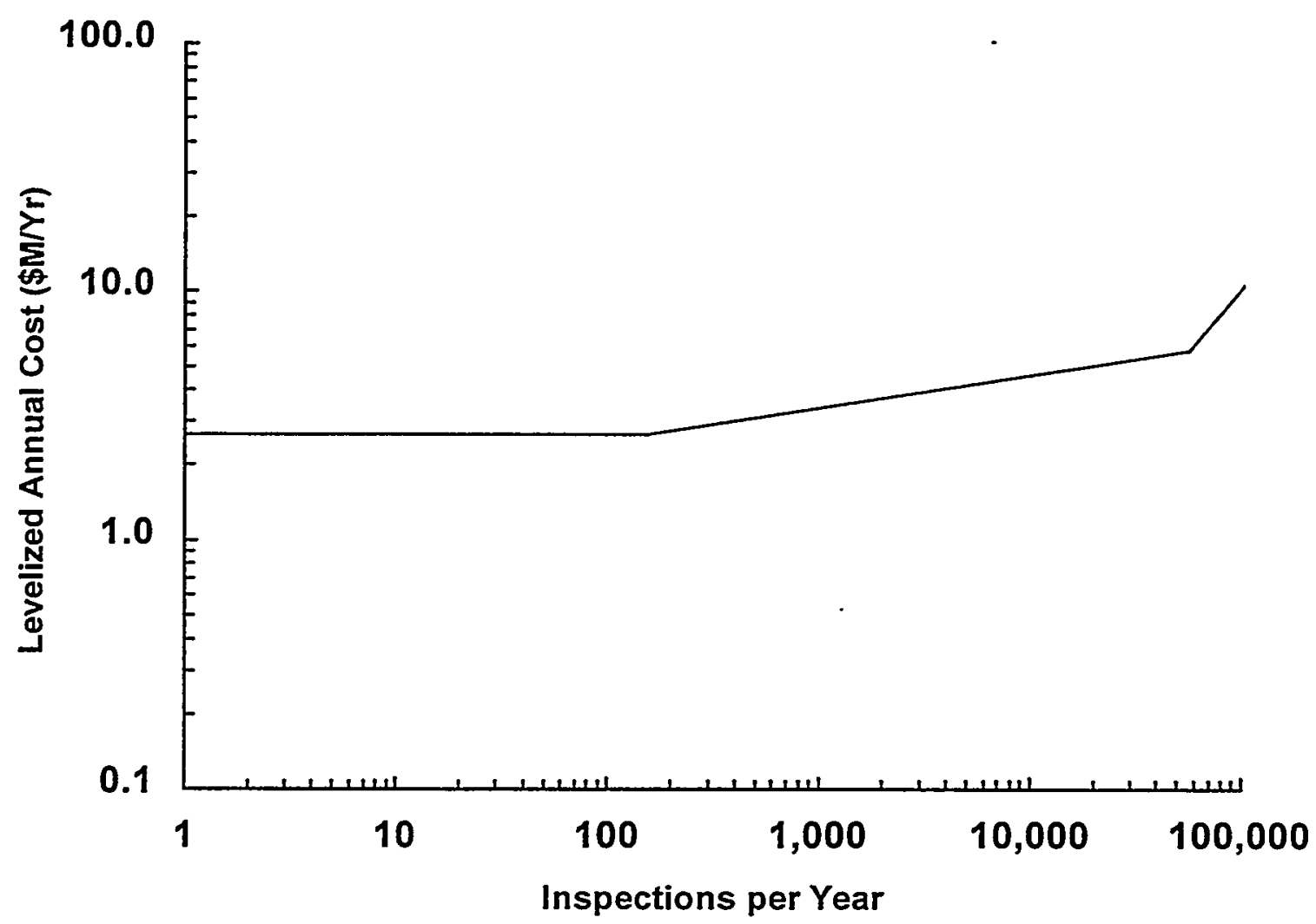

Figure 8. Silo Door Monitoring Cost

Random Monitoring Using Over-Flights with Manned Aircraft 


\section{Random Monitoring Using Over-Flights with Unmanned Aircraft}

We assume that unmanned over-flights would use visible light photography and infrared photography, just like manned over-flights, to image silo doors and the immediately surrounding area. We assume that these over-flights must catch uploading in the act.

We assume that an inspection team for a few inspection flights would consist of 2 inspectors-two pilots which also share imagery interpretation responsibilities--and an escort. The cost for a few (154) inspections (an inspection is the inspection of a single silo) is estimated to be $\$ 2.3 \mathrm{M}$ in Table E8. Since this option must catch uploading in the act, an aircraft and inspection team must be on alert at all times to allow random inspections; otherwise, the host country can upload missiles when the team is absent. We further assume that a full-time inspection team consists of 4 inspectors serving as both pilots and imagery interpreters and working in two shifts. In Table A-9, we estimate that a full time team will cost $\$ 4.5 \mathrm{M} / \mathrm{Yr}$. Aircraft capital (amortized over 10 years) and operating costs are shown in Table E7. We assume that an aircraft will be assigned to each full-time inspection team. The relation between inspection cost and annual number of inspections is shown in Figure 9 that was generated from Table E10.

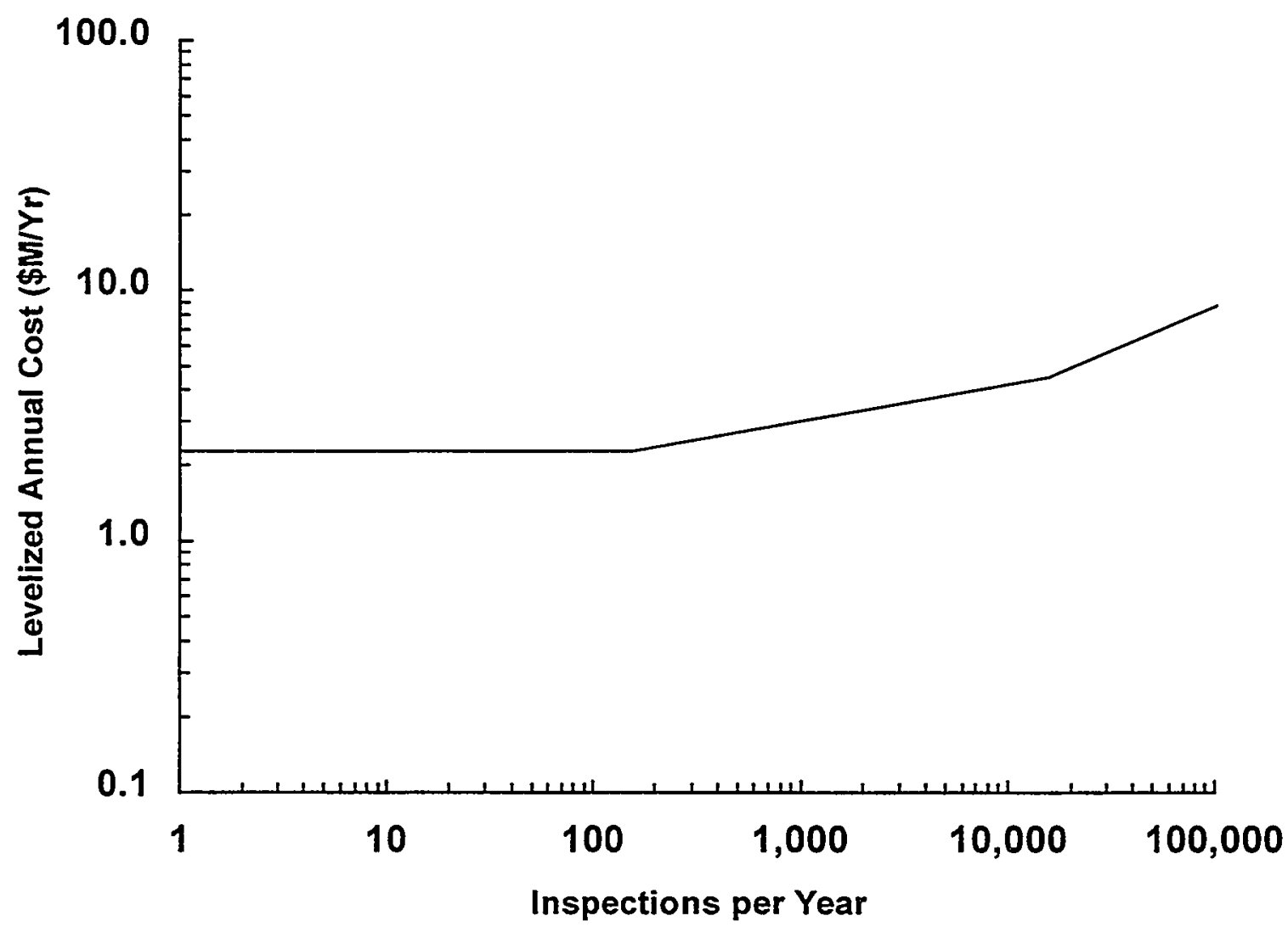

Figure 9. Silo Door Monitoring Cost

Random Monitoring Using Over-Flights with Unmanned Aircraft 


\section{Random Monitoring Using Satellites}

We assume that satellite over-flights must catch uploading in the act.

For small numbers of silo inspections, we assume that commercial satellites would be used to provide images. Our estimates for commercial image costs are shown in Table E11. At about 27,000 images per year a dedicated NTM satellite becomes cost effective and its cost (amortized over 10 years) is estimated in Table E12. We assume that for silo fields at the latitude of the SS18 fields, the satellite has an orbital inclination that produces a revisit time of 20 hours, and uses an operating team consisting of 6 people-- 1 operator for each 8 hour shift and 3 image interpreters. Since the satellite's revisit time is greater than the assumed time required to upload missiles (12 hours), the host country could upload when the satellite is out of view. Because of this, 2 satellites are needed, but we assume that they have other responsibilities that share in their cost. The relation between inspection cost and annual number of inspections is shown in Figure 10 , which was generated from Table E13.

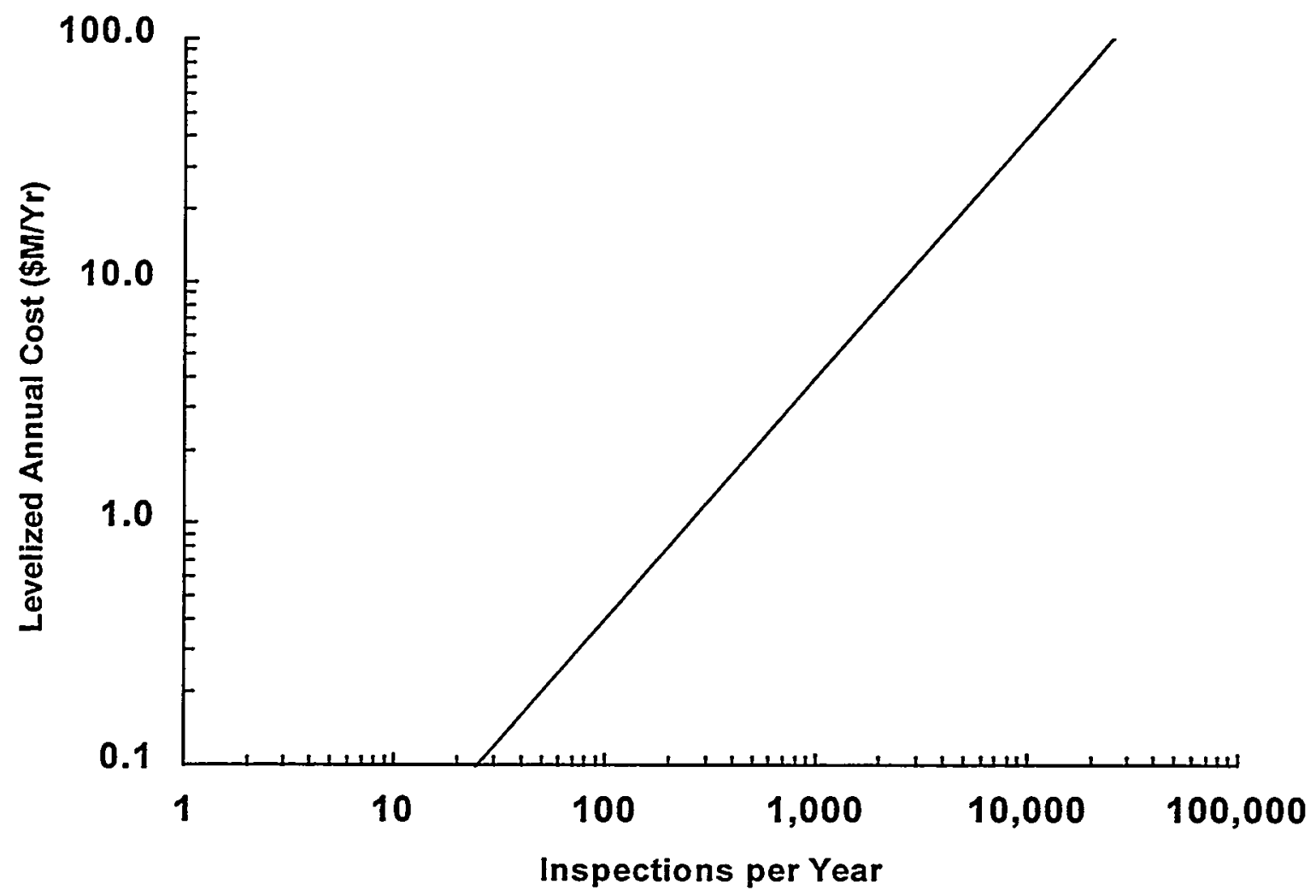

Figure 10. Silo Door Monitoring Cost Random Monitoring using Satellites 


\section{Continuous Monitoring Using Inspection Teams}

By continuous monitoring we do not mean that an inspector is present at each silo at all times. Instead, we mean that each silo is revisited with a time period shorter than the time required for uploading a missile. Since inspection is done continuously, inspectors need not look into silos or check door sensors. They need only confirm that the missiles are not being uploaded during the inspection. Each silo must be inspected at least every 12 hours since the estimated warhead replacement time is 12 hours.

We estimate that a team of inspectors can inspect one silo every 20 minutes and that 16 teams are required to continuously inspect all four fields. This inspection time assumes that inspectors do not have to gain access to a fenced silo site but can instead observe the silo at a short distance from outside the fence. We assume that each team consists of 3 inspectors and 2 escorts, and the teams work in shifts so that at least one team is on duty at all times. The inspectors would share driving, observation, and recording tasks. We estimate that 16 teams will cost $\$ 44.9$ million each year. The basis for the above estimates is developed in Appendix F, Table F1.

\section{Continuous Silo Inspection Cost $=\$ 44.9 \mathrm{M} / \mathrm{Yr}$}

\section{Continuous Monitoring Using Unmanned Aircraft}

This option would require two ground teams with two high-endurance, unmanned aircraft which operate continuously, except for aircraft maintenance, to monitor the four missile fields. The ground team would consist of 4 pilots who work in shifts and also serve as image analysts. Each silo would be covered an average of 2 times each day and, with proper scheduling, and the maximum time between inspections for any given silo would be 12 hours. The costs for this option are summarized in Table E9.

Continuous Monitoring Using Unmanned Aircraft Cost $=\$ 9.0 \mathrm{M} / \mathrm{Yr}$

\section{Continuous Remote Monitoring Using Unattended Door Sensors}

This option uses sensors applied to each silo door which transmit a signal by satellite up-link to confirm that the door has not been opened. The system will require multiple types of sensors at each silo. The sensors will relay an alarm if the door is opened or if the sensor is tampered with. Possible sensors considered in this analysis are magnetic door switches, fiber-optic seals, motion sensors, bistatic, encoded break-beams, and cameras. Appendix $\mathrm{F}$ shows estimated costs associated with remote, unattended monitoring for all 154 SS-18 silos. The figures are based on cost estimates provided by Corbell (1998). He estimates that an engineered, tamper resistant sensor package will cost roughly $\$ 22,000$ per silo. Corbell estimates that a three-man team can install and check out the system for one silo each day. Site modification costs can be extremely variable depending on the modifications required to attach sensors and on the availability of 
power. We assumed that site modifications will cost $\$ 5000$ per silo, but this figure is extremely variable. We further assume that a team must return to each silo once a year for sensor analysis, maintenance, and replacement. These costs are listed in Tables F2 and F3. This estimate amortizes the initial capital cost over 4 years, the expected duration of deactivation.

Remote Monitoring Cost Using Unattended Sensors \$3.6 M/Yr 


\section{Results and Conclusions}

Figure 11 combines the cost charts for the monitoring options into a single chart. It shows the relation between costs and the number of annual inspections. Costs for continuous monitoring options are shown on the chart as horizontal cost lines. Keep in mind that continuous monitoring is not associated with a specific number of inspections. We will compare the relative merits of each monitoring option by class and follow that with a comparison that cuts across classes.

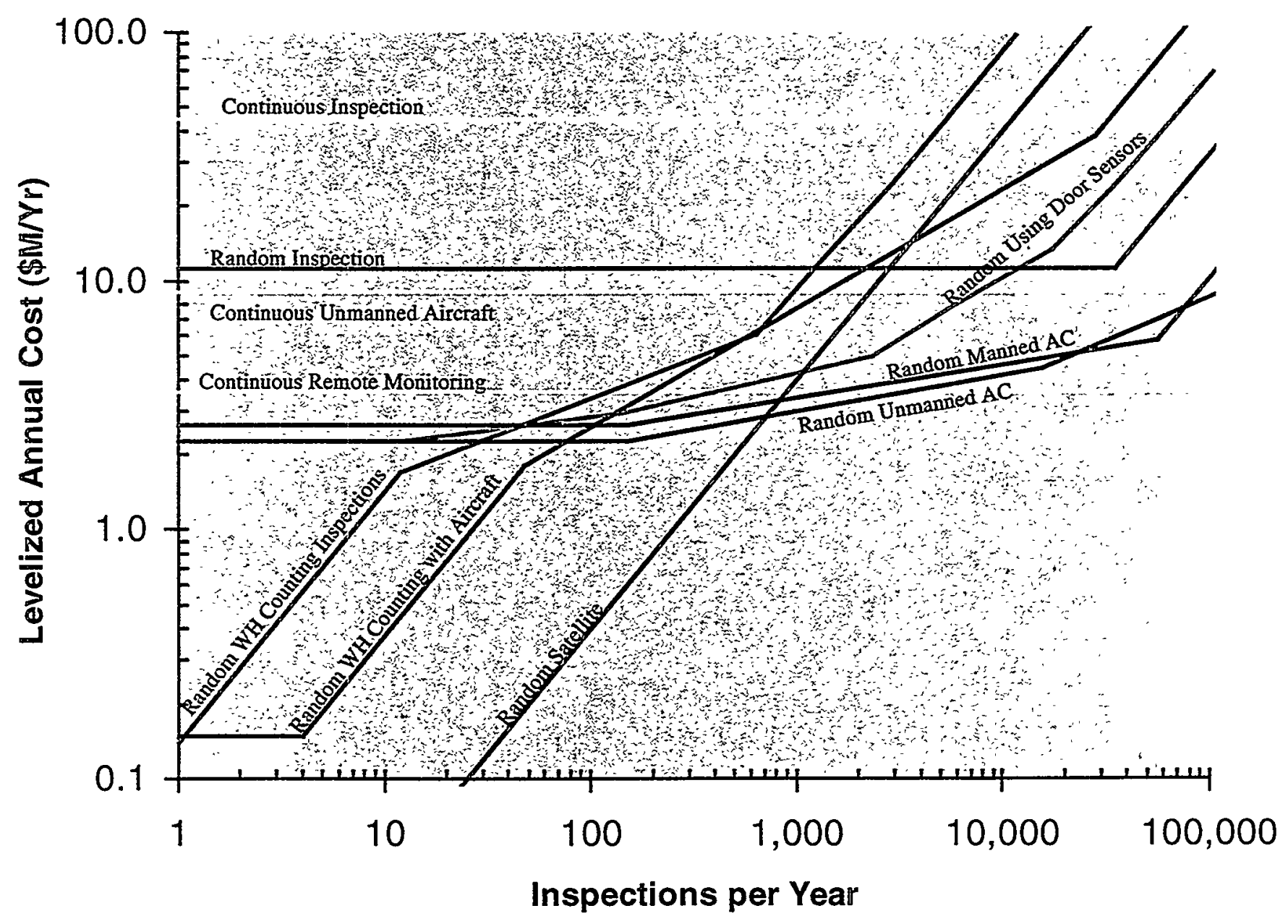

Figure 11. Silo Door Monitoring Costs 


\section{Random Monitoring With Confirmation}

The three blue lines (shades of blue are used to help distinguish among them) in Figure 11 show the relation between cost and the number of inspections per year for random monitoring with confirmation:

\section{Random monitoring with warhead counting inspections, Random monitoring with warhead counting using aircraft, and Random monitoring using door sensors.}

Random monitoring with warhead counting inspections (RV-OSIs) is generally the most expensive option. Random monitoring using warhead counting with aircraft is the least expensive option if fewer than 100 inspections are conducted each year, and random monitoring using silo door sensors is the least expensive option if more than 100 annual inspections are conducted. Random monitoring using door sensors is more expensive than warhead counting using aircraft with fewer than 100 annual inspections because of the fixed cost associated with applying sensors. With fewer than 100 annual inspections, the probability of detecting reactivation before a large number of missiles have been reactivated is low if 8 missiles can be uploaded each day and uploading takes 12 hours for each missile. According to Table A1 (Appendix A), we obtain 10\% probability of detection after 27 missiles are uploaded if we conduct 100 annual inspections, and, according to Table A5, we obtain $90 \%$ probability of detection only after 142 missiles ( $92 \%$ of the force) are uploaded if we conduct 100 annual inspections. For these reasons, more than 100 inspections a year are needed if we desire high probability of detecting uploading before a large number of missiles are uploaded; in which case, the least expensive option will be random monitoring using silo door sensors.

\section{Random Monitoring Without Confirmation}

The four red lines (including dark red for random unmanned aircraft) in Figure 9 show the relation between cost and the number of annual inspections for monitoring without confirmation:

Random monitoring using inspection teams,

Random monitoring using over-flights with manned aircraft, Random monitoring using over-flights with unmanned aircraft, and

Random monitoring using satellites.

Random inspection without confirmation is expensive because a large number of inspection teams are required to insure that missiles cannot be uploaded when an inspection team travels between sites. Unmanned aircraft appear to be slightly less expensive than manned aircraft over most of the inspection number range. Satellites are the least expensive option if fewer that about 500 annual inspections are performed. Manned and unmanned aircraft are the least expensive options if more than 500 annual inspections are conducted. (It is interesting to note that at 112,420 inspections per year, monitoring without confirmation using either inspectors, manned 
aircraft, or unmanned aircraft becomes equivalent to continuous monitoring since silos are inspected more frequently than the time required to upload them, assumed to be 12 hours.) If 500 annual inspections are conducted, we will only reach $10 \%$ probability of detection after 23 missiles are reactivated (Table B1 in Appendix B assuming 12 hours are required to reactivate each missile), and we cannot reach $90 \%$ probability of detection before all missiles have been reactivated (Table B5). Thus, random monitoring using over-flights with manned or unmanned aircraft are the least expensive options if high detection probability is desired before a large number of missiles have been reactivated. For the use of manned or unmanned aircraft to be practical, notification times before flights, if required, must be significantly shorter than the time required to upload a missile so that the inspections can be random. Although satellites are more expensive than unmanned aircraft if more than 500 annual inspections are conducted and randomness is an issue for satellite monitoring, satellites have the advantage that they are not restricted to looking only at silos and can detect other activities associated with uploading. In addition, notifications are not required before inspections.

\section{Continuous Monitoring}

Continuous monitoring gives a very high confidence that warheads, once removed, have not been replaced. The horizontal lines using yellow in Figure 9 represent the cost of continuous monitoring:

Continuous monitoring using inspection teams, Continuous monitoring using unmanned aircraft, and

Continuous remote monitoring using unattended door sensors.

Continuous inspection is expensive. Continuous remote monitoring has a significantly lower cost than continuous inspections and a lower cost than continuous monitoring using manned or unmanned aircraft. In fact, it has a lower cost than all other monitoring options considered if the frequency of monitoring is above a few thousand inspections each year. On the other hand, active technical monitoring is the most uncertain option relative to false alarms, failure rates, environmental sensitivity, and countermeasures--the criteria we do not cover in this study. Thus, active technical monitoring may be the best choice, but extensive evaluation will be required to prove the technology before that choice can be made.

\section{Comparing Across Monitoring Classes}

The different classes of monitoring options give different types of monitoring results making it difficult to select the best option unless a common monitoring criterion is established. Figure 12 combines the cost analysis shown in Figure 11 with detection probabilities. For comparison purposes, let us select the criterion that monitoring must insure $90 \%$ probability that uploading will be discovered before the host country can upload 30 missiles (20\% of the SS-18 force), given that he can upload 8 missiles each day and that it takes 12 hours to upload a missile. 
doors). The rightmost vertical dashed blue line in Figure 12 is at 2000 inspections per year and represents $90 \%$ detection probability before 30 missiles are uploaded if inspections are random and the presence or absence of uploading is confirmed. According to Table B5, roughly 9000 annual inspections must be performed to get the same detection probability (90\%) if the inspections do not confirm the absence or presence of uploading and depend on catching uploading in the act (inspections with doors closed and no door sensors or monitoring with satellites or aircraft). The rightmost vertical dashed red line in Figure 12 is at 9000 inspections per year and represents $90 \%$ detection probability before 30 missiles are uploaded if inspections are random and the presence or absence of uploading is not confirmed. Continuous monitoring inherently satisfies the $90 \%$ probability criterion.

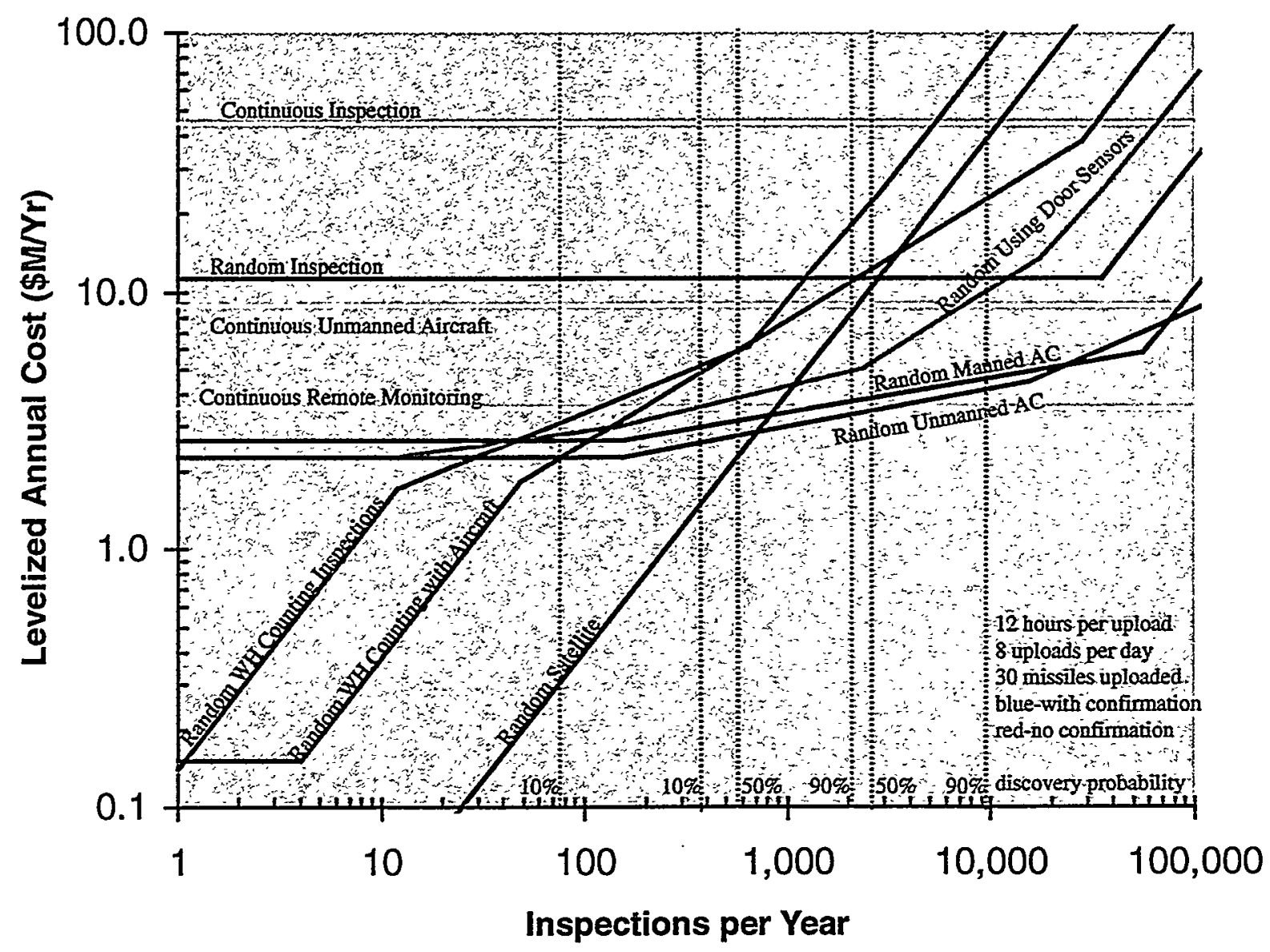

\section{Figure 12. Silo Door Monitoring Costs Dotted Lines Represent Detection Probability Levels Before 30 Missiles are Uploaded}

From Figure 12, the least expensive option for monitoring with confirmation at 2000 inspections per year is random inspection using silo door sensors with a cost of roughly $\$ 4.5 \mathrm{M} / \mathrm{Yr}$. Also from Figure 12, the least expensive option for monitoring without confirmation at 9000 inspections per year is random monitoring with manned or unmanned aircraft at roughly $\$ 3$ $\mathrm{M} / \mathrm{Yr}$. The cost for continuous remote monitoring is roughly $\$ 3.6 \mathrm{M} / \mathrm{Yr}$. The three monitoring 
technologies have comparable cost (within a factor of 2) and are therefore competitive for the stated criterion--90\% detection probability.

Random monitoring with confirmation at 2000 annual inspections, random monitoring without confirmation at 9000 annual inspections, and continuous monitoring all satisfy the $90 \%$ detection probability criterion and give us the same statistical confidence. However, while they give the same statistical confidence, they may not give us the same confidence in areas outside of statistics. As stated before, monitoring with confirmation and continuous monitoring practically assure that reactivation will be eventually caught in contrast to random monitoring without confirmation. In addition, some monitoring technologies may be more reliable or easier to use than others and we may have more experience with some than others. These additional issues must enter into our evaluation of confidence.

The additional vertical dashed lines in Figure 12 represent less stringent detection probabilities of $10 \%$ and $50 \%$ for detection before 30 missiles are uploaded assuming 8 missiles per day are uploaded and 12 hours is required for each upload. The same three monitoring options appear to be the least expensive even for the less stringent detection probabilities until the desired detection probability falls below roughly $20 \%$. Below $20 \%$ detection probability, satellite monitoring is the least expensive.

We can make monitoring requirements still less stringent by allowing more missiles to be reactivated before discovery. Figure 13 places vertical dashed lines at inspection-per-year values representing $10 \%, 50 \%$, and $90 \%$ probability that detection will occur before all 154 missiles have been reactivated assuming that 8 missiles can be uploaded each day and that 12 hours per upload is required. According to Figure 13, this case would favor monitoring using warhead counting with aircraft or using satellites. Satellites are less expensive than random monitoring using aircraft if a detection probability below $60 \%$ is allowed; however, the randomness issue must be resolved.

In conclusion, if we desire high confidence in detecting reactivation before a large fraction of the missile force is uploaded, three monitoring options appear to be the most promising:

- random monitoring using door sensors;

- random monitoring using manned or unmanned aircraft; and

- remote monitoring using unattended door sensors.

These three options are described in more detail in Appendices $\mathrm{G}, \mathrm{H}$, and I. Before adopting any of these monitoring options, further study is needed to resolve the technical issues associated with each. 


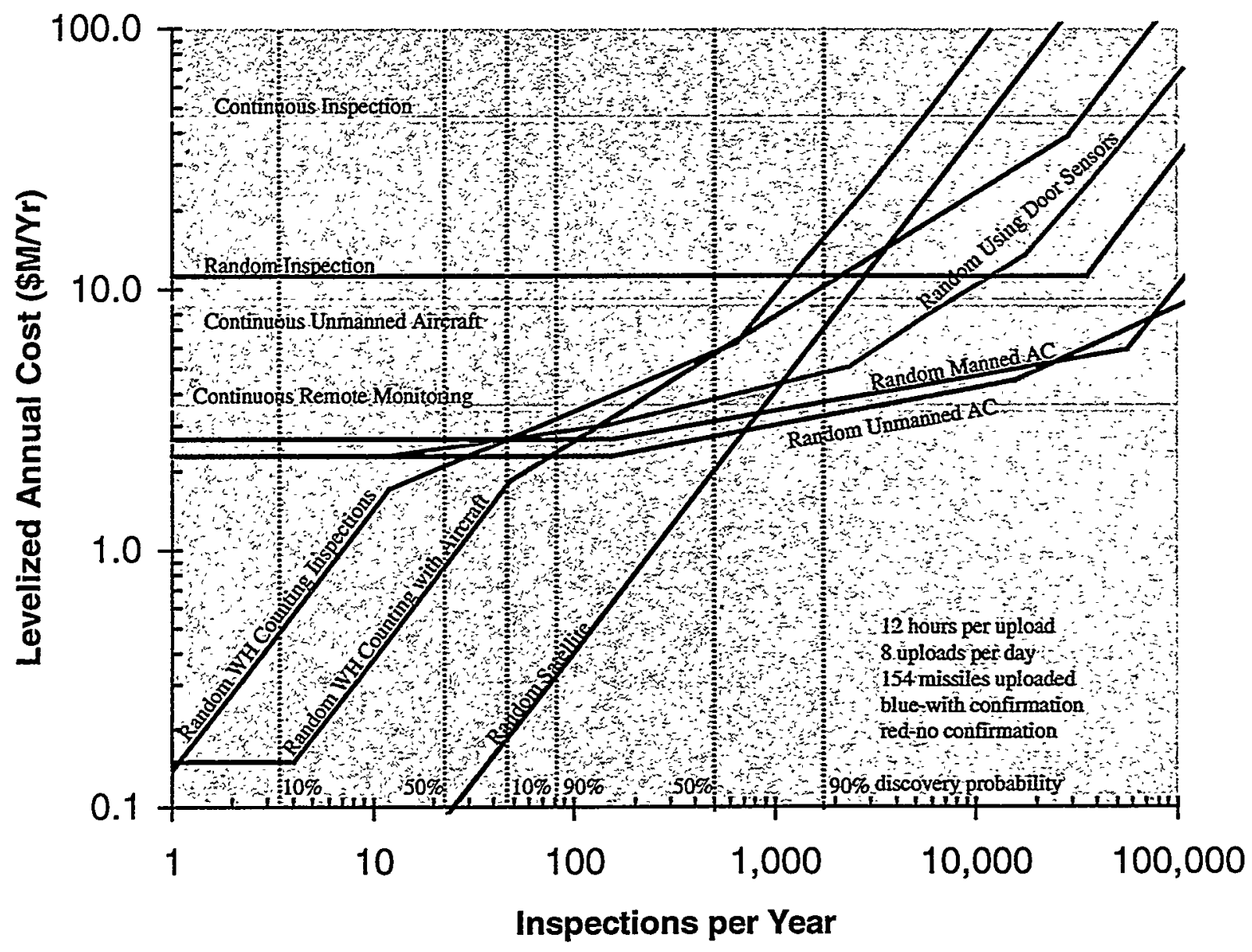

Figure 13. Silo Door Monitoring Costs

Dotted Lines Represent Detection Probability Level Before 154 Missiles are Uploaded 


\section{APPENDIX A. Missile Upload Detection Probabilities for Random Monitoring with Confirmation}

In this appendix, we estimate the probability of detecting uploads using monitoring options where inspectors confirm that the missiles remain downloaded or have been uploaded. In this case the silo doors are opened to allow an on-site or airborne inspection which counts warheads and confirms that missiles remain downloaded, or the doors remain closed and inspectors examine door sensors to confirm that the doors have not been opened to upload missiles. We consider a situation in which the Russians attempt to upload all of their missiles over a period of time. We want to estimate the time it will take to discover that one or more missiles have been uploaded given that they upload $\mathrm{N}$ missiles per day in randomly selected silos and that we conduct I total random inspections per year (an inspection is the inspection of one silo). In addition to counting warheads, there is a possibility that the inspection will catch uploading in the act. We assume that inspections are made with insufficient warning to allow the Russians to hide the evidence of uploading. This would require a significant departure from START protocol.

The probability that an inspection discovers an uploaded missile in the silo at time $\mathrm{t}_{\mathrm{i}}$ (which is the time of the $i^{\text {th }}$ inspection) is given by Equation A1. The probability that an inspection catches uploading in the act is given by Equation A2. Equation A2 assumes that an inspection is instantaneous. This assumption is slightly conservative because a real inspection will have a few minutes duration, and it will have a slightly higher probability of discovering uploading than an instantaneous inspection. The total probability that uploading is discovered by an inspection is given by Equation $\mathrm{A} 3$.

$$
\begin{aligned}
& P_{u}=N_{j} / M \\
& P_{a}=N T / M \\
& P_{i}=P_{u}+P_{a}-\left(P_{u}\right)\left(P_{a}\right)
\end{aligned}
$$

$\mathrm{N}$ - number of missiles uploaded in a day

i - inspection number since uploading began

$\mathrm{M}$ - total number of missiles

I - number of inspections per year

$\mathrm{T}$ - time, in days, required for uploading one missile

$\mathrm{Nt}_{\mathrm{i}}$ is the number of missiles that have been uploaded at time $\mathrm{t}_{\mathrm{i}}$ which is the time of the $\mathrm{i}^{\text {th }}$ inspection. Since the probability of discovering an uploaded missile during a single inspection is equal to the fraction of missiles uploaded, $\mathrm{Nt}_{\mathrm{i}} / \mathrm{M}$ is the probability that the inspection will discover an uploaded missile. NT is the number of missiles that are in the process of being 
uploaded at any given time. NT/M is the probability that the inspection of a single silo catches uploading in the act.

The probability that uploading is discovered on or before the $\mathrm{K}^{\text {th }}$ inspection is given by Equation A4.

$$
P_{d}=1-\Pi\left(1-P_{i}\right)
$$

$\Pi$ denotes the product from $i=1$ to $K$. The term $\Pi\left(1-P_{i}\right)$ is the probability that uploads are not discovered during the $\mathrm{K}$ inspections. Tables $\mathrm{A} 1$ through $\mathrm{A} 5$ show the relation between the number of missiles uploaded when various detection probability levels are obtained, the number of missiles uploaded each day, and the number of inspections conducted in a year assuming that there are 154 missiles and that the reload time is 12 hours.

Table A1. Number of Missiles Uploaded when 10\% Detection Probability is Obtained Random Inspection With Confirmation

154 Missiles, 12 Hour Reload Time

\begin{tabular}{|c|c|c|c|c|c|c|c|}
\hline $\begin{array}{l}\text { uploads/day } \overrightarrow{ } \\
\text { inspections/yx }\end{array}$ & 1 & 2 & 4 & 8 & 16 & 32 & 64 \\
\hline 1 & 109 & 153 & 154 & 154 & 154 & 154 & 154 \\
\hline 2 & 77 & 108 & 153 & 154 & 154 & 154 & 154 \\
\hline 5 & 48 & 68 & 96 & 135 & 154 & 154 & 154 \\
\hline 10 & 34 & 48 & 67 & 95 & 133 & 154 & 154 \\
\hline 20 & 24 & 34 & 47 & 66 & 92 & 129 & 154 \\
\hline 50 & 15 & 21 & 29 & 40 & 55 & 76 & 104 \\
\hline 100 & 10 & 14 & 20 & 27 & 37 & 49 & 65 \\
\hline 200 & 7 & 10 & 14 & 18 & 24 & 31 & 39 \\
\hline 500 & 4 & 6 & 8 & 10 & 13 & 16 & 19 \\
\hline 1000 & 3 & 4 & 5 & 6 & 8 & 9 & 10 \\
\hline 2000 & 2 & 2 & 3 & 4 & 4 & 5 & 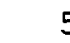 \\
\hline 5000 & 1 & 1 & 1 & 2 & 2 & 2 & 2 \\
\hline 10000 & 1 & 1 & 1 & 1 & 1 & 1 & 1 \\
\hline 20000 & 0 & 0 & 0 & 0 & 0 & 0 & c \\
\hline 50000 & 0 & 0 & 0 & 0 & 0 & 0 & $c$ \\
\hline 100000 & 0 & 0 & 0 & 0 & 0 & 0 & \\
\hline
\end{tabular}


Table A2. Number of Missiles Uploaded when 25\% Detection Probability is Obtained Random Inspection With Confirmation

154 Missiles, 12 Hour Reload Time

\begin{tabular}{|c|c|c|c|c|c|c|c|}
\hline $\begin{array}{l}\text { uploads/day } \rightarrow \\
\text { inspections/yr }\end{array}$ & 1 & 2 & 4 & 8 & 16 & 32 & 64 \\
\hline 1 & 154 & 154 & 154 & 154 & 154 & 154 & 154 \\
\hline 2 & 127 & 154 & 154 & 154 & 154 & 154 & 154 \\
\hline 5 & 80 & 113 & 154 & 154 & 154 & 154 & 154 \\
\hline 10 & 57 & 80 & 112 & 154 & 154 & 154 & 154 \\
\hline 20 & 40 & 56 & 79 & 111 & 154 & 154 & 154 \\
\hline 50 & 25 & 35 & 49 & 69 & 96 & 135 & 154 \\
\hline 100 & 18 & 25 & 34 & 48 & 66 & 91 & 126 \\
\hline 200 & 12 & 17 & 24 & 33 & 44 & 60 & 81 \\
\hline 500 & 8 & 10 & 14 & 19 & 26 & 33 & 42 \\
\hline 1000 & 5 & 7 & 10 & 13 & 16 & 20 & 24 \\
\hline 2000 & 4 & 5 & 6 & 8 & 10 & 12 & 13 \\
\hline 5000 & 2 & 3 & 3 & 4 & 5 & 5 & 6 \\
\hline 10000 & 1 & 2 & 2 & 2 & 2 & 3 & 3 \\
\hline 20000 & 1 & 1 & 1 & 1 & 1 & 1 & $I$ \\
\hline 50000 & 0 & 0 & 0 & 0 & 0 & 0 & 0 \\
\hline & 0 & 0 & 0 & 0 & 0 & 0 & 0 \\
\hline
\end{tabular}

Table A3. Number of Missiles Uploaded when 50\% Detection Probability is Obtained Random Inspection With Confirmation

154 Missiles, 12 Hour Reload Time

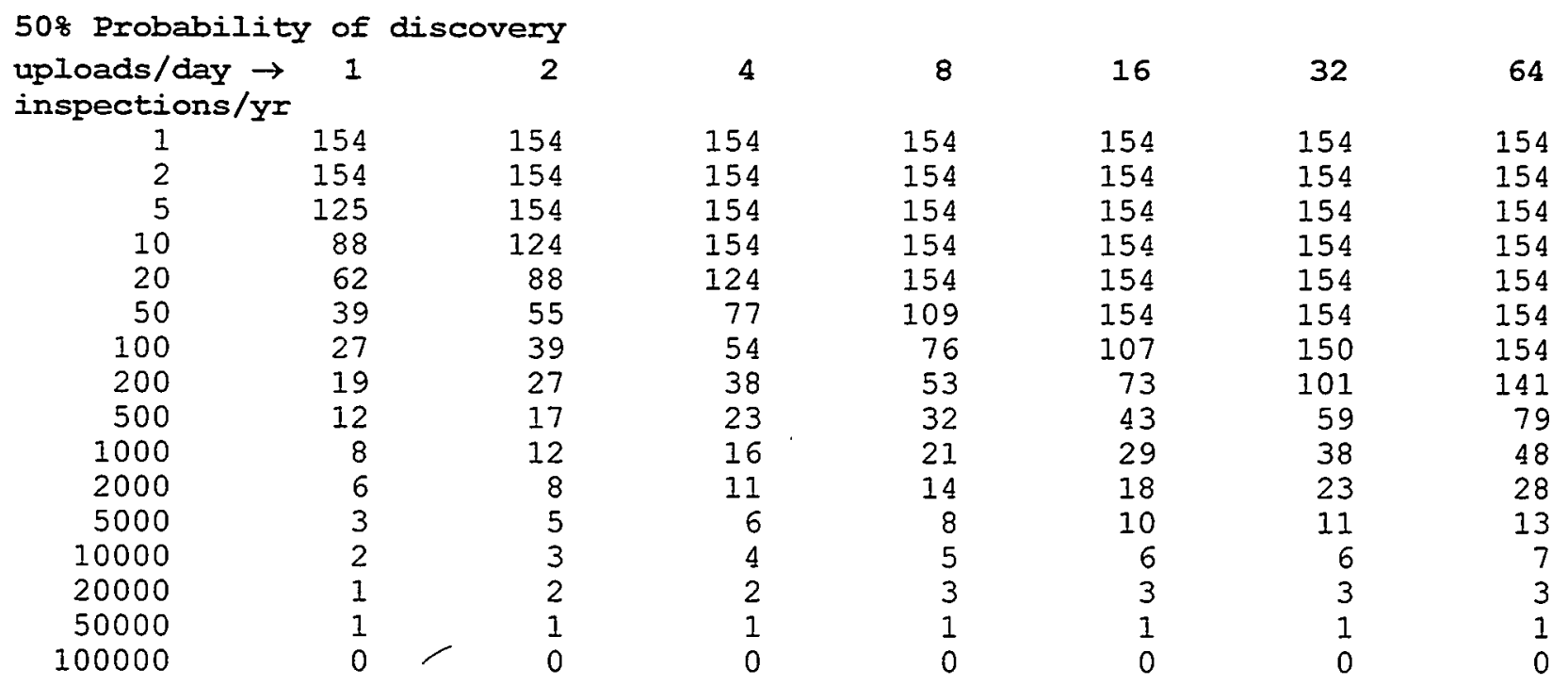


Table A4. Number of Missiles Uploaded when 75\% Detection Probability is Obtained Random Inspection With Confirmation

154 Missiles, 12 Hour Reload Time

$\begin{array}{rrrrrrrr}\begin{array}{l}\text { 758 Probability } \\ \text { uploads/day } \rightarrow \\ \text { inspections/yr }\end{array} & 1 & 2 & 4 & 8 & 16 & 32 & 64 \\ 1 & 154 & 154 & 154 & 154 & 154 & 154 & 154 \\ 2 & 154 & 154 & 154 & 154 & 154 & 154 & 154 \\ 5 & 154 & 154 & 154 & 154 & 154 & 154 & 154 \\ 10 & 125 & 154 & 154 & 154 & 154 & 154 & 154 \\ 20 & 88 & 124 & 154 & 154 & 154 & 154 & 154 \\ 50 & 55 & 78 & 110 & 154 & 154 & 154 & 154 \\ 100 & 39 & 55 & 77 & 109 & 154 & 154 & 154 \\ 200 & 27 & 39 & 54 & 76 & 107 & 150 & 154 \\ 500 & 17 & 24 & 34 & 47 & 65 & 89 & 123 \\ 1000 & 12 & 17 & 23 & 32 & 43 & 59 & 79 \\ 2000 & 8 & 12 & 16 & 21 & 29 & 38 & 48 \\ 5000 & 5 & 7 & 9 & 12 & 16 & 20 & 24 \\ 10000 & 3 & 5 & 6 & 8 & 10 & 11 & 13 \\ 20000 & 2 & 3 & 4 & 5 & 6 & 6 & 7 \\ 50000 & 1 & 2 & 2 & 2 & 2 & 2 & 3 \\ 100000 & 1 & 1 & 1 & 1 & 1 & 1 & 1\end{array}$

Table A5. Number of Missiles Uploaded when 90\% Detection Probability is Obtained Random Inspection With Confirmation

154 Missiles, 12 Hour Reload Time

\begin{tabular}{|c|c|c|c|c|c|c|c|}
\hline $\begin{array}{l}\text { uploads/day } \rightarrow \\
\text { inspections/yr }\end{array}$ & 1 & 2 & 4 & 8 & 16 & 32 & 64 \\
\hline 1 & 154 & 154 & 154 & 154 & 154 & 154 & 154 \\
\hline 2 & 154 & 154 & 154 & 154 & 154 & 154 & 154 \\
\hline 5 & 154 & 154 & 154 & 154 & 154 & 154 & 154 \\
\hline 10 & 154 & 154 & 154 & 154 & 154 & 154 & 154 \\
\hline 20 & 113 & 154 & 154 & 154 & 154 & 154 & 154 \\
\hline 50 & 72 & 101 & 143 & 154 & 154 & 154 & 154 \\
\hline 100 & 50 & 71 & 100 & 142 & 154 & 154 & 154 \\
\hline 200 & 36 & 50 & 70 & 99 & 140 & 154 & 154 \\
\hline 500 & 22 & 31 & 44 & 61 & 85 & 119 & 15 \\
\hline 1000 & 16 & 22 & 30 & 42 & 58 & 80 & 110 \\
\hline 2000 & 11 & 15 & 21 & 29 & 39 & 52 & 69 \\
\hline 5000 & 7 & 9 & 13 & 17 & 22 & 29 & \\
\hline 10000 & 5 & 6 & 8 & 11 & 14 & 17 & 20 \\
\hline 20000 & 3 & 4 & 5 & 7 & 8 & 10 & 1 \\
\hline 50000 & 2 & 2 & 3 & 3 & 4 & 4 & \\
\hline 100000 & 1 & 1 & 2 & 2 & 2 & 2 & \\
\hline
\end{tabular}

This relationship will be true for any type of random inspection which confirms that the missile being inspected has not been uploaded. Although we have assumed that inspections are random, complete randomness is not required provided inspection patterns are sufficiently random to prevent the inspected country from observing an inspection pattern which they can use to delay the discovery of uploaded missiles. 


\section{APPENDIX B. Missile Upload Detection Probabilities for Random Monitoring without Confirmation}

In this case, silo doors remain closed, warheads are not counted, and sensors are not used to confirm that doors have remained closed. Monitoring must catch uploading in the act. We want to estimate the time it will take to discover that one or more missiles have been uploaded given that $\mathrm{N}$ missiles are uploaded per day in randomly selected silos and that we conduct I total random inspections each year (an inspection is the inspection of one silo).

The probability that an upload will be detected in the act on the $\mathrm{i}^{\text {th }}$ inspection is given by Equation B1. This equation assumes that an inspection is instantaneous. The assumption is slightly conservative because a real inspection will have a few minutes duration, and it will have a slightly higher probability of discovering uploading than an instantaneous inspection.

$$
P_{i}=N T / M
$$

$\mathrm{N}$ - number of missiles uploaded in a day

$\mathrm{T}$ - the time in days required to upload warheads on a single missile (we estimate $1 / 2$ day)

$\mathrm{M}$ - total number of missiles

i - inspection number since uploading began

I - number of inspections per year

NT is the number of missiles being uploaded at any given time. NT/M is the probability that the random inspection of a single silo will catch uploading in the act. The probability that $\mathrm{K}$ inspections will discover uploading is given by Equation B2.

$$
P_{d}=1-\left(1-P_{i}\right)^{K}
$$

The term $\left(1-\mathrm{P}_{\mathrm{i}}\right)^{\mathrm{K}}$ is the probability uploads are not discovered during the $\mathrm{K}$ inspections. Tables B1 through B5 show the relation between number of missiles uploaded when a prescribed detection probability level is obtained, the number of missiles uploaded per day, and the number of inspections conducted each year.

This relationship will be true for any type of random inspection without confirmation by inspectors, satellites, or aircraft assuming that the inspections are sufficiently random to avoid a pattern of which the inspected country can take advantage. The number 999 denotes that the whole missile force can be uploaded without reaching the prescribed detection probability. 
Table B1. Number of Missiles Uploaded when $10 \%$ Detection Probability is Obtained Random Inspection Without Confirmation

154 Missiles, 12 Hour Reload Time

$10 \%$ Probability of detection

$\begin{array}{crrrrrrr}\begin{array}{l}\text { uploads/day } \rightarrow \\ \text { inspections/Yr }\end{array} & \mathbf{1} & \mathbf{2} & \mathbf{4} & \mathbf{8} & 16 & 32 & 64 \\ 1 & 999 & 999 & 999 & 999 & 999 & 999 & 999 \\ 2 & 999 & 999 & 999 & 999 & 999 & 999 & 999 \\ 5 & 999 & 999 & 999 & 999 & 999 & 999 & 999 \\ 10 & 999 & 999 & 999 & 999 & 999 & 999 & 999 \\ 20 & 999 & 999 & 999 & 999 & 999 & 999 & 999 \\ 50 & 999 & 999 & 999 & 999 & 999 & 999 & 999 \\ 100 & 118 & 118 & 118 & 118 & 118 & 118 & 118 \\ 200 & 59 & 59 & 59 & 59 & 59 & 59 & 59 \\ 500 & 23 & 23 & 23 & 23 & 23 & 23 & 23 \\ 1000 & 11 & 11 & 11 & 11 & 11 & 11 & 11 \\ 2000 & 5 & 5 & 5 & 5 & 5 & 5 & 5 \\ 5000 & 2 & 2 & 2 & 2 & 2 & 2 & 2 \\ 10000 & 1 & 1 & 1 & 1 & 1 & 1 & 1 \\ 20000 & 0 & 0 & 0 & 0 & 0 & 0 & 0 \\ 50000 & 0 & 0 & 0 & 0 & 0 & 0 & 0 \\ 10000 & 0 & 0 & 0 & 0 & 0 & 0 & 0\end{array}$

Table B2. Number of Missiles Uploaded when 25\% Detection Probability is Obtained Random Inspection Without Confirmation 154 Missiles, 12 Hour Reload Time

\begin{tabular}{|c|c|c|c|c|c|c|c|}
\hline $\begin{array}{l}\text { uploads/day } \rightarrow \\
\text { inspections/yr }\end{array}$ & 1 & 2 & 4 & 8 & 16 & 32 & 64 \\
\hline 1 & 999 & 999 & 999 & 999 & 999 & 999 & 999 \\
\hline 2 & 999 & 999 & 999 & 999 & 999 & 999 & 999 \\
\hline 5 & 999 & 999 & 999 & 999 & 999 & 999 & 999 \\
\hline 10 & 999 & 999 & 999 & 999 & 999 & 999 & 999 \\
\hline 20 & 999 & 999 & 999 & 999 & 999 & 999 & 999 \\
\hline 50 & 999 & 999 & 999 & 999 & 999 & 999 & 999 \\
\hline 100 & 999 & 999 & 999 & 999 & 999 & 999 & 999 \\
\hline 200 & 999 & 999 & 999 & 999 & 999 & 999 & 999 \\
\hline 500 & 64 & 64 & 64 & 64 & 64 & 64 & 64 \\
\hline 1000 & 32 & 32 & 32 & 32 & 32 & 32 & 32 \\
\hline 2000 & 16 & 16 & 16 & 16 & 16 & 16 & 16 \\
\hline 5000 & 6 & 6 & 6 & 6 & 6 & 6 & 6 \\
\hline 10000 & 3 & 3 & 3 & 3 & 3 & 3 & 3 \\
\hline 20000 & 1 & 1 & 1 & 1 & 1 & 1 & 1 \\
\hline 50000 & 0 & 0 & 0 & 0 & 0 & 0 & 0 \\
\hline 100000 & 0 & 0 & 0 & 0 & 0 & 0 & 0 \\
\hline
\end{tabular}


Table B3. Number of Missiles Uploaded when 50\% Detection Probability is Obtained Random Inspection Without Confirmation 154 Missiles, 12 Hour Reload Time

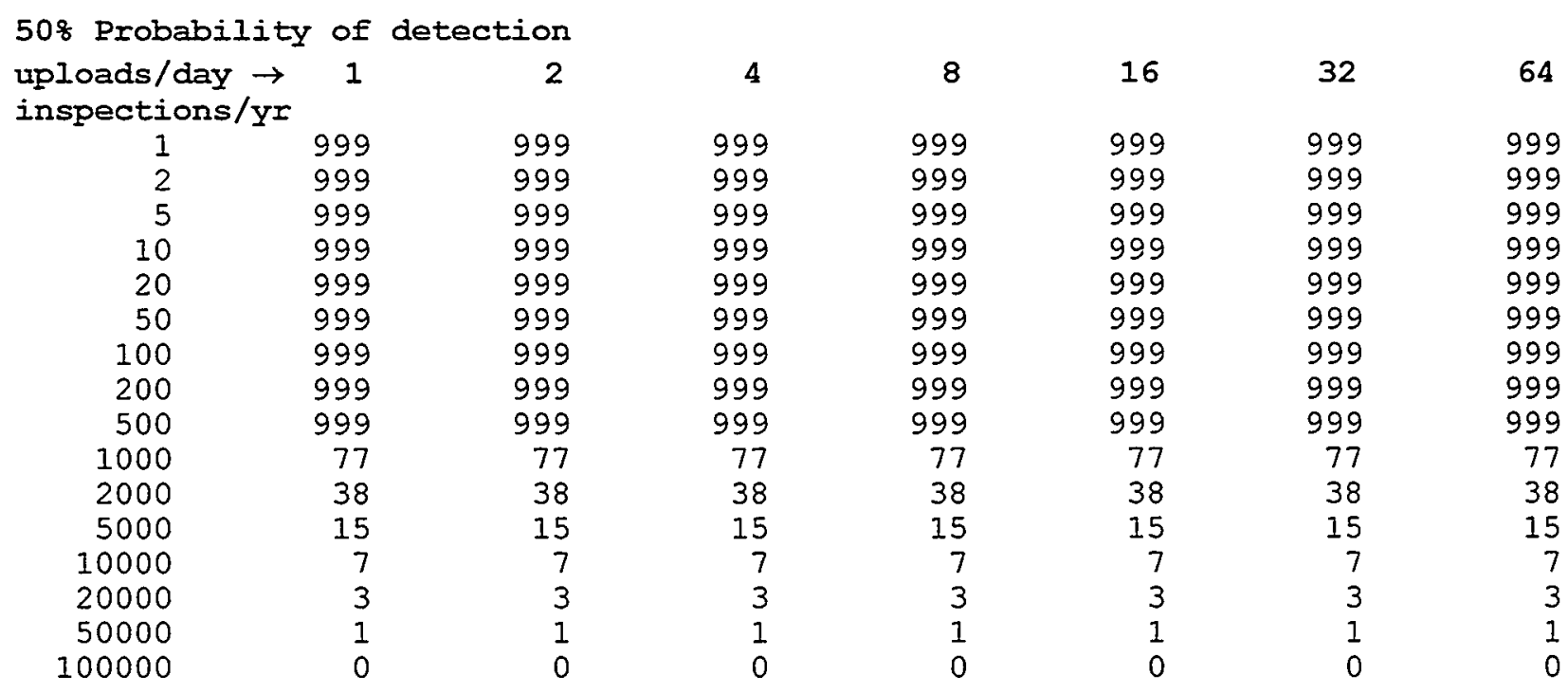

Table B4. Number of Missiles Uploaded when 75\% Detection Probability is Obtained Random Inspection Without Confirmation 154 Missiles, 12 Hour Reload Time

$75 \%$ Probability of detection

uploads/day $\rightarrow \quad 1 \quad 2$

inspections/yx

$\begin{array}{rrr}1 & 999 & 999 \\ 2 & 999 & 999 \\ 5 & 999 & 999 \\ 10 & 999 & 999 \\ 20 & 999 & 999 \\ 50 & 999 & 999 \\ 100 & 999 & 999 \\ 200 & 999 & 999 \\ 500 & 999 & 999 \\ 1000 & 999 & 999 \\ 2000 & 77 & 77 \\ 5000 & 31 & 31 \\ 10000 & 15 & 15 \\ 20000 & 7 & 7 \\ 50000 & 3 & 3 \\ 100000 & 1 & 1\end{array}$

$\begin{array}{rrrrr}4 & 8 & 16 & 32 & 64 \\ 999 & 999 & 999 & 999 & 999 \\ 999 & 999 & 999 & 999 & 999 \\ 999 & 999 & 999 & 999 & 999 \\ 999 & 999 & 999 & 999 & 999 \\ 999 & 999 & 999 & 999 & 999 \\ 999 & 999 & 999 & 999 & 999 \\ 999 & 999 & 999 & 999 & 999 \\ 999 & 999 & 999 & 999 & 999 \\ 999 & 999 & 999 & 999 & 999 \\ 999 & 999 & 999 & 999 & 999 \\ 77 & 77 & 77 & 77 & 77 \\ 31 & 31 & 31 & 31 & 31 \\ 15 & 15 & 15 & 15 & 15 \\ 7 & 7 & 7 & 7 & 7 \\ 3 & 3 & 3 & 3 & 3 \\ 1 & 1 & 1 & 1 & 1\end{array}$


Table B5. Number of Missiles Uploaded when $90 \%$ Detection Probability is Obtained Random Inspection Without Confirmation

154 Missiles, 12 Hour Reload Time

$\begin{array}{cccr}908 \text { Probability } & \text { of detection } & \\ \begin{array}{c}\text { uploads/day } \rightarrow \\ \text { inspections/yr }\end{array} & 1 & 2 & 4 \\ 1 & 999 & 999 & 999 \\ 2 & 999 & 999 & 999 \\ 5 & 999 & 999 & 999 \\ 10 & 999 & 999 & 999 \\ 20 & 999 & 999 & 999 \\ 50 & 999 & 999 & 999 \\ 100 & 999 & 999 & 999 \\ 200 & 999 & 999 & 999 \\ 500 & 999 & 999 & 999 \\ 1000 & 999 & 999 & 999 \\ 2000 & 129 & 129 & 129 \\ 5000 & 51 & 51 & 51 \\ 10000 & 25 & 25 & 25 \\ 20000 & 12 & 12 & 12 \\ 50000 & 5 & 5 & 5 \\ 100000 & 2 & 2 & 2\end{array}$

8
999
999
999
999
999
999
999
999
999
999
129
51
25
12
5
2

16
999
999
999
999
999
999
999
999
999
999
129
51
25
12
5
2

32
999
999
999
999
999
999
999
999
999
999
129
51
25
12
5
2




\section{APPENDIX C. \\ General Assumptions About Monitoring Manpower and Cost Estimates}

For manpower and cost estimates in the following appendices, we use a set of uniform assumptions to gain consistency among estimates for different types of monitoring. Costs are expressed in thousands of dollars, $\$ \mathrm{k}$.

$\begin{array}{lc}\text { Work days per year } & 220 \\ \text { Salaries } & 80 \$ \mathrm{k} / \text { man-year for all personnel } \\ \text { Overhead factor } & 2 \\ \text { International air fare } & 1.2 \$ \mathrm{k} / \text { flight } \\ \text { Per diem living expenses } & 0.2 \$ \mathrm{k} / \text { inspector-day } \\ \text { Local transportation } & 0.1 \$ \mathrm{k} / \text { team-day } \\ \text { Program Management add-on } & 60 \% \\ \text { Number of missiles } & 154 \\ \text { Number of missile fields } & 4 \text { in two pairs of two } \\ \text { Travel time between silos } & 10 \text { minutes (roughly } 6 \mathrm{~km} \text { at } 36 \mathrm{~km} / \mathrm{hr} \text { ) } \\ \text { Travel time between fields in a pair } & 1 \text { day (roughly } 500 \mathrm{~km} \text { at } 500 \mathrm{~km} / \text { day) } \\ \text { Travel time between pairs of fields } & 3 \text { days (roughly } 1500 \mathrm{~km} \text { at } 500 \mathrm{~km} / \text { day) }\end{array}$

Examples to show how these numbers will be used in the cost and manpower estimates are as follows:

A three-man inspection team will require more than three inspectors over a year because we assume that each inspector works 220 days each year and inspectors would have to be rotated to accommodate vacations and other time off. If a team consists of three inspectors who are on the job every day, then the total number of inspectors required is 3 inspectors per team $\times 365$ days per year / 220 work days per year $=4.98$ inspectors (the analysis will allow fractional numbers of people).

Salary for inspectors is 3 inspectors per team x $80 \mathrm{k} \$$ /inspector-year $\times 2$ overhead $\times 365$ days per year $/ 220$ work days per year $=796.4 \$ \mathrm{k} /$ year.

If each team member requires 4 international flights each year, the international travel cost is 3 inspectors $\times 4$ flights per inspector per year x $1.2 \mathrm{k} \$ /$ flight $\times 365$ days per year / 220 work days per year $=23.9 \$ \mathrm{k} /$ year.

Monitoring costs include both initial costs (equipment, engineering, design, installation, etc.) and annual operating costs (maintenance, inspection, communications, etc.). Some monitoring options, for example inspections, have relatively low initial costs and relatively high operating costs; and other options, for example technical monitoring, have relatively high initial costs and relatively low operating costs. To compare options with dissimilar cost flows we use a 
discounted cash flow analysis (Stermole, 1980) to annualize or amortize initial costs. In other words, we find the annual cash flow that is equivalent to an initial expenditure and add it to annual operating costs. If a remote monitoring system will only be used for four years, as is the probable case for deactivation monitoring, then its initial cost must be amortized over four years. Thus, the expected life of the system impacts its annualized cost. For aircraft and satellites we use a 10 year amortization which assumes a service life beyond the missile deactivation application.

In the following cost analyses, we use the term inspection to mean the inspection of a single silo. During an inspection trip, several inspections may be conducted. 


\section{APPENDIX D. \\ Manpower and Cost Estimates for Random Monitoring with Confirmation}

\section{Random Monitoring with Warhead Counting Inspections}

For this monitoring option, an inspection team travels to the silo being inspected, escorts open the silo door, inspectors confirm that the missile's RVs have been removed, and escorts close the silo door. We assume that a warhead counting inspection team consists of 7 inspectors, necessary vehicles, living quarters, and administrative and support personnel. In addition, we assume that 4 escorts are required. The inspecting country will not pay for escorts. Those costs will be paid by the host country. However, the inspecting country will pay for escorts when it serves as the host country, so we have included escort costs.

The cost for the inspection team and escorts to perform a single inspection is estimated in Table D1. We assume that a single inspection requires 10 days for the inspectors. The inspectors require four days "in-country" with one of those being an inspection day. Two days are spent for international travel and the other four for briefings and debriefings. We also assume that escorts are required for four days to cover the four days spent in-country by the inspection team. These times approximate the practice of the OSIA used in START RV-OSIs.

\begin{tabular}{|c|c|}
\hline & $\$ \mathrm{k}$ \\
\hline \multicolumn{2}{|l|}{7 man inspection team } \\
\hline salaries & 51 \\
\hline international travel & 8 \\
\hline living expenses \& local transportation & 14 \\
\hline \multicolumn{2}{|l|}{4 escorts } \\
\hline salaries & 12 \\
\hline living expenses & 3 \\
\hline Program management @60\% & 53 \\
\hline Total cost per inspection & $\overline{142}$ \\
\hline
\end{tabular}

We assume that a full time team, which is resident in the host country, can inspect 2 silos each day, and can inspect a field in 20 days. Inspecting all 4 fields requires 4 X 20 inspection days plus 8 travel days between the four fields. Thus, the team inspects 154 silos in 88 days and 639 silos each year. The cost for a team that performs full time warhead-counting inspections is estimated in Table D2. 
Table D2. Cost for a Full Time Warhead counting Inspection Team

$\begin{array}{lr}7 \text { man inspection team } & 1858 \\ \text { salaries } & 56 \\ \text { international travel } & 511 \\ \text { living expenses } & 37 \\ \text { local transportation } & \\ 4 \text { escorts } & 1062 \\ \text { salaries } & 292 \\ \text { living expenses } & 2289 \\ \text { Program management @ 60\% } & 6104\end{array}$

If there are two full-time teams resident in the host country, each team will inspect 2 fields which requires only 2 travel days between the 2 fields instead of 8 travel days among 4 fields. With 4 or more teams, inter-field travel is not necessary.

\section{Table D3. Numbers of Annual Inspections and Cost for Warhead Counting Inspection Teams}

$\begin{array}{rrrr}\text { Teams } & \text { Inspections } / \mathrm{Yr} & & \$ \mathrm{k} / \mathrm{Yr} \\ & 1 & 142 \\ 1 & 12 & 1,704 \\ 2 & 639 & 6,104 \\ 4 & 1,338 & 12,209 \\ 8 & 2,920 & 24,418 \\ 16 & 5,840 & 48,835 \\ & 11,680 & 97,670\end{array}$

\section{Random Monitoring with Warhead.Counting Using Aircraft}

For this monitoring option, host country ground crews open silo doors, an inspection team flies over the opened silos to visually examine and photograph the interior, and ground crews close silo doors. We estimate the annualized cost of a manned aircraft in Table D4 (Air Force 1989, Ginsberg 1998, Bradley, 1998). We assume that monitoring requires a visible light camera and an infrared camera. Monitoring may also require synthetic aperture radar but we have not included it in this cost estimate. We assume that visible and infrared cameras can be used in clear weather and that the airplane can fly below clouds in cloudy weather. Radar would be useful with foggy conditions, but, since available data indicates that foggy conditions are infrequent at the silo sites, we did not include radar. The annualized aircraft cost is estimated 
using a service life of 10 years. If the project is shorter than 10 years, we assume that the aircraft will be used for other projects. If the aircraft is used for a single inspection trip, we assume that it must be "rented" for two weeks at a rate equal to the annualized cost multiplied by $2 / 52$.

Table D4. Manned Aircraft Cost

$\begin{array}{lrr}\text { Aircraft (Fairchild Metro type) } & \frac{\$ \mathrm{k}}{4170} \underline{\$ \mathrm{k} / \mathrm{Yr}} \\ \text { Camera } & 300 \\ \text { IR Camera } & 200 \\ \text { Data Processing equipment } & 30 & \\ \text { Training } & 50 & \\ \text { Total initial cost } & 4750 & \\ 4750 \text { \$k amortized over 10 years at 5\% (.130 annualization factor) } & 618 \\ \text { Maintenance contract } & 350 \\ \text { Fuel } & 246 \\ \text { Total annualized cost at 10 years amortization } & 1214\end{array}$

We assume that an inspection team consists of a pilot, a copilot, an instrument operator, an escort, and host country ground-teams of three men each who open and close silo doors for inspection.

For a single inspection trip, we assume that 10 days are required for the inspection team--two days for travel, 4 days for briefings and debriefings, and 4 days in-country which includes one day of inspection. We assume that a single ground-team is used for a single inspection trip and that the ground-team requires four days for an inspection trip. One day is for opening silo doors, two days are for travel, and one day is for briefings and debriefings. We assume that each ground-team is capable of opening and closing 4 silo doors each day and that 4 silos will be inspected during a single inspection trip. 


\section{Table D5. Cost for a Single Monitoring Trip for a Manned Over-Flight}

\section{Warhead Counting Team}

$\begin{array}{lr}3 \text { man inspection team } & \underline{\$ \mathrm{k}} \\ \quad \text { salaries } & 22 \\ \text { international travel } & 4 \\ \text { living expenses } & 6 \\ 1 \text { escort } & 3 \\ \text { salaries } & 1 \\ \text { living expenses } & \\ 3 \text { man ground team } & 9 \\ \quad \text { salaries } & 3 \\ \quad \text { living expenses \& local transportation } & 47 \\ \text { Aircraft and sensors } & 57 \\ \text { Program management @ 60\% } & 152 \\ \text { Total cost per inspection trip } & \end{array}$

For a full time inspection team we have added an image interpreter to make a team of 4 inspectors. A full time inspection team can potentially conduct 77 inspections each day $(28,105$ each year) if the silos are opened by 20 ground-teams. Monitoring cost will be very dependent on the number of ground teams supported by the host country.

\section{Table D6. Cost for a Full Time Manned Over-Flight Warhead Counting Monitoring Team}

4 man inspection team

$\begin{array}{lr}\text { salaries } & 1,062 \\ \text { international travel } & 32 \\ \text { living expenses } & 292\end{array}$

1 man escort

$\underline{\$ \mathrm{k}}$

salary

20-3man ground teams

salaries

15,927

living expenses $\quad 4,380$

local transportation $\quad 730$

Aircraft and sensors

1,214

Program management@60\%

Total cost per team

14,386

38,362 
Table D7 summarizes the cost for inspections using warhead counting with manned aircraft. With four inspections per year, we assume that a single ground team is used and that the aircraft inspects four silos during the one-day inspection trip. We also assume that inspecting a single silo would cost the same as inspecting four silos. With 48 annual inspections, we assume that the single inspection trip is repeated each month. For larger numbers of inspections, we assume that the aircraft is used full time and that 20 ground teams for each aircraft are available to open silo doors.

Table D7. Relation Between Cost and Annual Number of Inspections with Warhead Counting Using Aircraft

\begin{tabular}{|c|c|c|}
\hline Aircraft & Inspections / Yr & $\$ \mathrm{k} / \mathrm{Yr}$ \\
\hline 1 & 1 & $\overline{152}$ \\
\hline 1 & 4 & 152 \\
\hline 1 & 48 & 1,824 \\
\hline 1 & 28,105 & 38,362 \\
\hline 2 & 56,210 & 76,724 \\
\hline 3 & 84,315 & 115,086 \\
\hline
\end{tabular}




\section{Random Monitoring Using Door Sensors}

For this monitoring option, inspectors place a tamper resistant sensor package on silo doors immediately following confirmation that the missile's RV section has been removed, and an inspection team returns periodically to confirm that sensors are in place and have not been tampered with, and to interrogate the sensors for evidence of door openings. The sensors are not passive. We assumed the use of sensors that actively sense door openings, faults, and tampering and store data within the sensor's enclosure because we believe that they will be more resistant to tampering than passive seals. The cost of installing silo door sensors is estimated in Table D8 based on information provided by Corbell (1998). We assume that the installation team stays in the country for 12 days at a time with 10 of those being work days. We amortize sensor installation cost by multiplying it by an annualization factor. The factor is based on a service life of both 4 and 10 years for the equipment. We use only the 4 year case for comparative analysis since the missile deactivation application we are considering will have a duration of 4 years.

\section{Table D8. Silo Door Sensor Cost}

Development

Sensor package (\$5k each $\mathrm{x} 154)$

Data acquisition (\$7k each $\times 154$ )

Power supply ( $\$ 1 \mathrm{k}$ each $\mathrm{x} 154)$

Enclosure (\$5k each $\times 154)$

Equipment shipping (10\% of sensor system cost)

Site Modification $154 @ \$ 5000$

3 man installation team, 154 silos at 1 per day

salaries

international travel (1 trip per man every 2 weeks)

living expenses

local transportation

training $(\$ 50,000)$

2 man escort team

salaries

living expenses

Total initial cost

$1384 \$ \mathrm{k}$ amortized over 4 years at 5\% (.282 annualization factor)

1384 \$k amortized over 10 years at 5\% (.130 annualization factor)

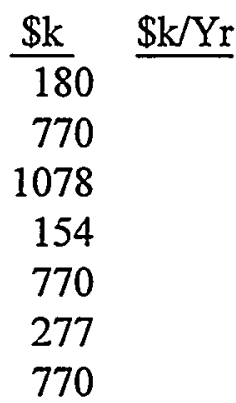

336

55

111

15

50

224

74

4865

1372

632

We assume that a monitoring team that inspects sensors placed on silo doors will require 3 inspectors, necessary vehicles, living quarters and administrative and support personnel, and 2 escorts. We include escorts in our cost estimates because they will be required by the host country. We assume that each country monitors the other and, although the inspecting country will not pay for the host country's escorts, that country will pay for escorts when it serves as the host country. 
We assume that a single inspection trip requires 10 days for the inspectors and 4 days for the escorts (as it did for a warhead counting inspection). We also assume that the team conducts 12 inspections, the number that can be conducted in one day (see below), during one trip.

Table D9. Cost for a Single Inspection Trip Using Door Sensors

3 man inspection team

salaries

$\$ \mathrm{k}$

international travel

22

living expenses \& local transportation $\quad \cdot \quad 6$

2 escorts

salaries

6

living expenses 2

Sensors

1372

Program management @60\%

Total cost per inspection trip

Table D10 shows our cost estimate for funding a full time monitoring team.

Table D10. Full Time Monitoring Team Cost for Door Sensor Inspections

3 inspectors

Salaries

$\$ \mathrm{k} / \mathrm{Yr}$

4 international trips per inspector

796

Living expenses

24

Local transportation

219

2 escorts

Salaries

531

Living expenses

146

Sensors

1372

Program management @60\%

1875

Total annual cost per team

$\frac{1875}{4999}$

We assume that a sensor inspection requires 40 minutes per silo: 30 minutes for the inspection and 10 minutes for travel between silos. Twelve silos are inspected per 8 hour day; inspecting one field requires 4 days; inspecting four fields requires 24 days ( $4 \times 4+8$ travel days between the fields); thus 154 silos are inspected in 24 days. If there are two teams, each team will inspect 
2 fields which requires only 2 travel days between the 2 fields instead of 8 travel days between 4 fields. With 4 teams, inter-field travel is not necessary.

Table D11 combines the above costs to show total costs associated with number of inspections. The cost of a single inspection trip that inspects 12 silos is $\$ 2,258 \mathrm{k}$, and we assume that inspecting a single silo would cost the same. For 12 inspections per year we assume that a single trip is made and that 12 silos are inspected. For 144 inspections, we assume that monthly inspection trips are made. For larger numbers of inspections we assume full time inspection teams.

Table D11. Number of Annual Inspections and Cost for Inspection Teams which Examine Silo Door Sensors

$\begin{array}{crrr}\text { Teams } & \text { inspections / Yr } & & \$ \text { K k/Yr } \\ & 1 & & 2,258 \\ & 12 & 2,258 \\ & 144 & 2,963 \\ 1 & 2,342 & 4,999 \\ 2 & 5,621 & 7,805 \\ 4 & 17,520 & 13,414 \\ 8 & 35,040 & 24,634\end{array}$




\section{APPENDIX E. \\ Manpower and Cost Estimates for \\ Random Monitoring Without Confirmation}

\section{Random Monitoring Using Inspection Teams}

For this type of monitoring, teams travel to each silo but silo doors are not opened and door sensors are not used. Uploading must be caught in the act. At least one inspection team is required at each of the four fields since travel time between fields is greater than warhead replacement time, and warheads could be replaced while inspectors are traveling between fields. We estimate that a team can inspect one silo every 20 minutes $(10$ minute inspection plus 10 minutes travel between silos), 24 silos each 8 hour day, and 8760 silos each year. Four teams can inspect 35,040 silos each year. We estimate the cost of a full time inspection team in Table E1.

Table E1. Cost for a Full Time Random Monitoring Inspection Team

\begin{tabular}{lr} 
& $\$ \mathrm{\$ k} / \mathrm{Yr}$ \\
\hline inspectors & \\
Salaries & 796 \\
4 international trips per inspector & 24 \\
Living expenses & 219 \\
Local transportation & 37 \\
2 escorts & 531 \\
$\quad$ Salaries & 146 \\
$\quad$ Living expenses & 1052 \\
Program management @ 60\% & 2,804 \\
Total annual cost per team & 11,216 \\
Total annual cost for 4 teams &
\end{tabular}

Table E2 summarizes numbers of inspections and costs. While at least 1 team is required at each field to allow for the possibility of random inspections, the teams could do a single random inspection in a year with the same cost as 35,040 inspections.

Table E2. Number of Annual Inspections and Cost for Inspection Teams with Silo Doors Closed and No Sensors

$\begin{array}{rrrr}\frac{\text { Teams }}{4} & \text { inspections / Yr } & & \frac{\$ \mathrm{k} / \mathrm{Yr}}{11,216} \\ 4 & 1 & & 11,216 \\ 8 & 35,040 & & 12,432 \\ 16 & 70,080 & & 24,864\end{array}$




\section{Random Monitoring Using Over-Flight with Manned Aircraft}

For this monitoring option the team flies over each silo, visually inspects, and takes pictures to confirm that doors are closed and there is no loading equipment around silos. The cost of an instrumented manned aircraft is estimated in Table E3 (Air Force 1989, Ginsberg 1998, Bradley, 1998). (This is the same table as D4.) We assume that monitoring requires a visible light camera and an infrared camera. Monitoring may also require synthetic aperture radar but we have not included it in this cost estimate. We assume that visible and infrared cameras can be used in clear weather and that the airplane can fly below clouds in cloudy weather. Radar would be useful with foggy conditions, but, since foggy conditions are infrequent, we did not include radar. We amortize aircraft and equipment cost over 10 years because they will be reusable if the monitoring project ends before their 10 year service life expires.

\section{Table E3. Manned Aircraft Cost}

Aircraft (Fairchild Metro type)

$\begin{array}{rr}\frac{\$ \mathrm{k}}{4170} & \$ \mathrm{k} / \mathrm{Yr} \\ 300 & \\ 200 & \\ 30 & \\ 50 & \\ 4750 & \\ & 618 \\ & 350 \\ & 246 \\ & 1214\end{array}$

Camera

IR Camera

Data Processing equipment

Training

618

Total initial cost

Maintenance contract

1214

Total annualized cost at 10 years amortization

We assume that a manned over-flight inspection team used to conduct a minimal number (we use 154) of inspections consists of 2 inspectors--2 pilots who double as sensor operators and imagery interpreters. Even though a minimal number of inspections are conducted each year, we believe that the inspection team and its aircraft must be in place and on alert at all times. Otherwise, the host country could upload missiles when the team is absent knowing that it would require more than 12 hours to get the team and aircraft into place. Thus, we assume that the aircraft cost for a minimal number of inspections is the same as that for full time inspection except for fuel and maintenance costs which we will assume to be negligible. The cost for a minimal number of inspections is shown in Table E4.

The estimated cost of a full time manned over-flight team is shown in Table E5. We use a 5-man inspection team. They are divided into two shifts of 2 pilots and an imagery interpreter. The pilots also serve as sensor operators. We assume that the aircraft is used for two shifts each day and covers all four fields (154 missiles) including the flight time to and from fields. The aircraft operates each day to perform 56,210 inspections per year. 
Table E4. Cost for a Minimal Number (154) of Manned Over-Flight Inspections

$\$ \mathrm{k}$

2 man inspection team

salaries

531

international travel

16

living expenses

146

1 man escort

salary 266

living expenses $\quad 73$

Aircraft and sensors 618

Program management @60\% $\quad \frac{989}{2638}$
Total cost per team

Total cost per team

Table E5. Cost for a Full Time Manned

Over-Flight Inspection Team

$\begin{array}{lr}5 \text { man inspection team } & \underline{\$ \mathrm{k} / \mathrm{Yr}} \\ \quad \text { salaries } & 1327 \\ \quad \text { international travel } & 40 \\ \quad \text { living expenses } & 365 \\ 2 \text { man escort } & \\ \quad \quad \text { salary } & 531 \\ \quad \text { living expenses } & 146 \\ \text { Aircraft and sensors } & 1214 \\ \text { Program management @ 60\% } & \underline{2174} \\ \text { Total cost per team } & 5796\end{array}$

While we call 154 inspections per year a minimal number, the team could do a single inspection for the same cost as 154 .

Table E6. Number of Annual Inspections and Cost for Manned Over-Flight Inspection Teams

\begin{tabular}{crr} 
Teams & inspections $/ \mathrm{Yr}$ & \\
\cline { 1 - 2 } 1 & $15 \mathrm{k} / \mathrm{Yr}$ \\
1 & 154 & 2,638 \\
1 & 56,210 & 2,638 \\
2 & 112,420 & 5,796 \\
& & 11,592
\end{tabular}




\section{Random Monitoring Using Over-Flight with Unmanned Aircraft}

For this monitoring option an unmanned aircraft (UAV) is flown over each silo and takes pictures to confirm that the door is closed and there is no loading equipment around the silo. A high endurance Predator with a cruising speed of roughly $200 \mathrm{~km} / \mathrm{hr}$ is an appropriate aircraft for this application because of the distances that must be covered. The cost of equipment that includes a Predator UAV, a visible light camera, and an infrared camera is estimated in Table E7 (Bolton, 1998, Ginsberg 1998). We amortize aircraft and equipment cost over 10 years. If the project is shorter than 10 years, we assume that the aircraft will be used for other projects.

\section{Table E7. Unmanned Predator Aircraft Cost}

$\begin{array}{lrr} & \$ \mathrm{k} & \$ \mathrm{k} / \mathrm{Yr} \\ \text { Unmanned Aircraft } & 2500 & \\ \text { TV \& IR Sensors } & 376 & \\ \text { Data Processing equipment } & 30 & \\ \text { Training } & 50 & \\ \text { Total initial cost } & 2956 & \\ \text { Amortized over 10 years at 5\% (.130 annualization factor) } & 384 \\ \text { Maintenance } & 286 \\ \text { Fuel } & 66 \\ \text { Total annualized cost at 10 years amortization } & 736\end{array}$

We assume that for a small number of unmanned over-flight inspections, the team will consist of 2 inspectors who share piloting and imagery interpretation tasks and a single escort. We also assume that the team must be in place, at a central location such as Omsk, and on alert at all times to insure that an inspection can be performed at any random time. Table E8 estimates the cost for a few (we use 154) inspections. We assume that maintenance and fuel cost are negligible if only a few inspections are conducted. 


\section{Table E8. Cost for a Few Unmanned Over-Flights (154 inspections)}

\begin{tabular}{lr} 
& $\$ \mathrm{k} / \mathrm{Yr}$ \\
\cline { 2 - 2 } 2 man inspection team & \\
salaries & 531 \\
international travel & 16 \\
living expenses & 146 \\
1 man escort & \\
$\quad$ salary & 266 \\
$\quad$ living expenses & 73 \\
Aircraft & 384 \\
Program management @ $60 \%$ & $\frac{849}{2265}$ \\
Total cost &
\end{tabular}

If the team is expanded to include 4 inspectors ( 2 teams of 2 operating in 2 shifts) who share piloting and image interpretation and 2 escorts, we estimate that a single UAV can conduct 15,700 inspections in a year. In order to ensure true randomness, the aircraft must be able to fly from any place on its flight path to any silo within twelve hours. Otherwise, silos that were out of range of the UAV could be uploaded and the silo door closed before the aircraft arrived. The Predator can fly from any point on its flight path to any selected silo in less than 12 hours.

The distance between the eastern two fields and western two fields is roughly $1600 \mathrm{~km}$ and would require 8 hours of flight time between the two most distant fields and another roughly 1.2 hours to inspect a field. If host country personnel see the UAV flying east from a centrally located base, they would know that 13 hours are available for uploading missiles in the western fields (4 hours UAV travel from Omsk to an eastern field, 1.2 hours for inspecting the eastern field, and 8 hours for the UAV to travel from the eastern field to the western field). This would give them time to upload some missiles. However, if the UAV is likely to turn around at any point and head for a western field, the host country can count on at most 8 hours for uploading, which is not sufficient. If the inspecting country establishes a predictable pattern, randomness is lost, and undetected uploading is possible. We assumed that inspection patterns are avoided except when a UAV inspects a field, in which case we assumed that it inspects the whole field before leaving. Even with this assumption, each silo can be reached within 9.2 hours, which does not give enough time for uploading without discovery. We estimated, using a Monte-Carlo model, that roughly 15,700 silos can be inspected each year with a single UAV. This estimate assumes that the UAV flies $75 \%$ of the time and is grounded for service the other $25 \%$.

If a more advanced UAV were available which could cruise at $350 \mathrm{~km} / \mathrm{hr}$ or faster, it would be able to cover all silos in a 12 hour period. in this case, having the aircraft turn around on a random basis and head toward another field would not be necessary since it could fly from any point on its path to any silo in less than 12 hours. With a cruise speed of $350 \mathrm{~km} / \mathrm{hr}$, a single unmanned aircraft could cover 56,210 silos each year if it was in the air for 12 hours each day; however, this analysis does not consider such an aircraft. 


\section{Table E9. Cost for Full-time Over-flights using One UAV}

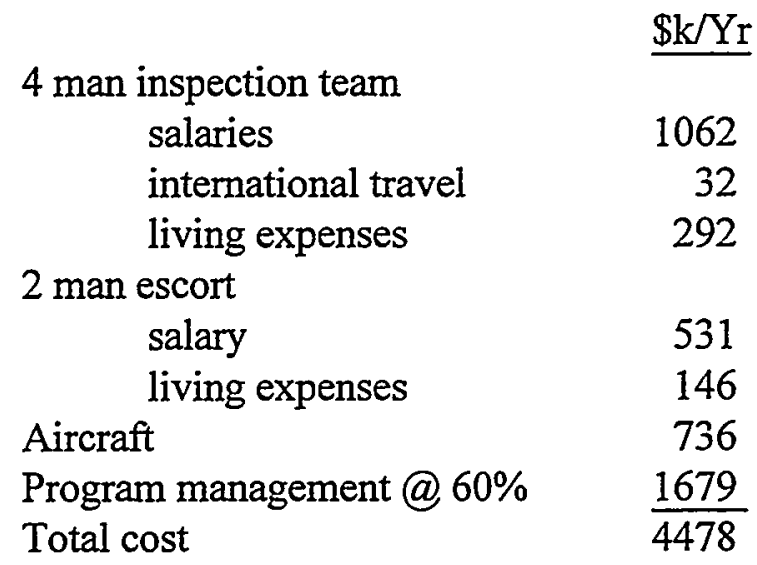

If two aircraft and two teams are used, we assume that one team is based at one of the eastern fields and the other is based at one of the western fields. We assume that a team consists of 4 pilots who double as imagery interpreters, and 2 escorts to cover two work shifts. With two aircraft, each silo can be monitored every 12 hours, which provides continuous monitoring. Thus, the UAV can inspect 112,420 silos each year.

The total cost based on the annual number of inspections is shown in Table E10. We assume that the cost of inspecting a single silo is the same as inspecting 154 silos.

Table E10. Number of Annual Inspections and Cost for Unmanned Over-Flight Inspection Teams

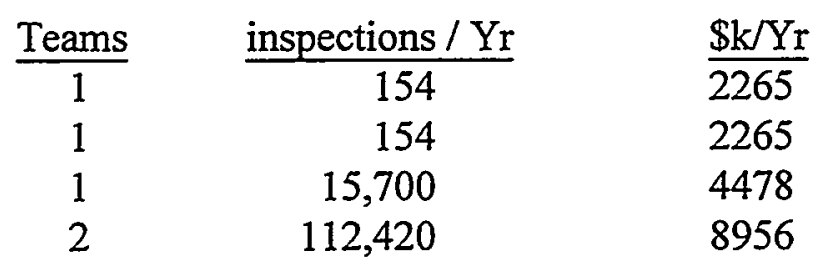




\section{Random Monitoring Using Satellites}

For this monitoring option, we assume that satellites are used to photograph silos and their surrounding areas. Commercial satellites are used until the cost associated with an increasing number of inspections justifies launching a satellite dedicated to silo door monitoring. Commercial satellite images cost $\$ 3700$ each and cover an $11 \mathrm{~km}$ square (Budge, 1998). We estimate that the average image can cover 1.5 silos. The associated costs are shown in Table E11.

\section{Table E11. Commercial Satellite Image Cost}

$\begin{array}{lc} & \$ \mathrm{k} \\ \text { Cost per image } & 3.7 \\ \text { Silos per image } & 1.5 \\ \text { Processing cost per silo } & .017 \\ \text { Subtotal per silo } & 2.5 \\ \text { Management } & 1.5 \\ \text { Total cost per silo } & 4.0\end{array}$

Table E12 estimates the cost of a satellite and ground station. We assume that 6 people will be needed each day to run the system and interpret the images (Brock, 1998).

\section{Table E12. Satellite Cost}

Satellite

Ground Station

Total initial cost

$515,000 \$ \mathrm{k}$ amortized over 10 years at $5 \%$ (.130 annualization factor)

Maintenance

6 man team salaries

Management

Total annualized cost $\frac{\$ \mathrm{k}}{500,000} \$ \mathrm{k \textrm {k }} / \mathrm{Yr}$

15,000

515,000

66,950

20

1,593

$\underline{41,138}$

109,700

The cost of 27,425 annual silo images is equivalent to the cost of 1 satellite, and if more images are required, then it is more economical to launch a satellite. For the orbit we considered, the satellite will fly over the same spot every 20 hours; thus, the satellite can image all 154 silos every 20 hours and 67,452 silos each year. To achieve inspection randomness, several, multipurpose satellites would be required, and they would be randomly tasked to photograph silos. We did not charge the cost of several multipurpose satellites to the silo door monitoring task. Instead, we assumed that silo door monitoring would pay for its share of the constellation. Table E13 summarizes monitoring costs using satellites. 


\title{
Table E13. Number of Annual Inspections and Cost for Satellite Imaging
}

$\begin{array}{ccc}\text { inspections / Yr } & & \frac{\$ \mathrm{k} / \mathrm{Yr}}{4} \\ 27,425 & & 109,700 \\ 67,452 & & 109,700 \\ 134,904 & & 219,400\end{array}$

\begin{abstract}
A possible future option is the use of DARPA Discoverer II satellites. The Discoverer II program will launch a large constellation of satellites using high resolution SAR. The primary mission of Discoverer II is wartime reconnaissance. In peacetime, it could be used to image silo doors. The resolution goal is $30 \mathrm{~cm}$, which should enable reliable detection of open silo doors. 24 to 48 satellite constellations are planned. Given 24 satellites, $770 \mathrm{~km}$ altitude, 65 degree inclination, and circular orbits, it is easy to design a constellation that would permit 1 hour revisit times at the missile fields. Given this revisit time, on the order of 1.3 million inspections a year could be conducted. Assuming that an image every 12 hours would be sufficient to detect any upload activities, then 112,400 inspections a year would be sufficient.
\end{abstract}

If silo door inspections could be conducted during the satellites "free time," then the only cost might be for equipment and analysts to examine the imagery. However, it is more likely that these satellites will be in demand and their use will not be free. 


\section{APPENDIX F. Manpower and Cost Estimates for Continuous Monitoring}

\section{Continuous Monitoring Using Inspection Teams}

By continuous monitoring, we mean that a monitoring team is stationed near the missile field at all times and that the time between inspections is less than the time required to upload a missile. We do not mean that an inspector is stationed at each silo at all times. An inspection consists of looking over the fence to confirm that the silo door is not open and that there is no $\mathrm{RV}$ loading equipment in the vicinity. We assume that an inspection team can inspect one silo every 20 minutes allowing 10 minutes for inspection plus 10 minutes for travel between silos. A team can inspect 24 silos per 8 hour day; four teams are required to inspect a field of 39 silos every 12 hours; and sixteen teams are required to continuously inspect all four fields

We assume that each team consists of 3 inspectors with 2 escorts and necessary vehicles, living quarters and administrative and support personnel. We include escorts in our cost estimates because escorts will be required by the host country. We assume that each country monitors the other, and although the inspecting country will not pay for the host country's escorts, it will pay for escorting their inspectors when it serves as the host. Table F1 shows our cost estimate for funding an inspection team.

Table F1. Inspection Team Cost for Continuous Inspections

3 inspectors

Salaries

$\$ \mathrm{k} / \mathrm{Yr}$

4 international trips per inspector

796

Living expenses

24

Local transportation

2 escorts

Salaries 531

Living expenses $\quad 146$

Program management @ 60\% $\quad \underline{1052}$

Total annual cost per team $\quad \frac{1052}{2,804}$

Total annual cost for 4 teams $\quad 11,216$

Total annual cost for 16 teams $\quad 44,868$

Cost for continuous monitoring using inspection teams $=\$ 44,868 \mathrm{k} / \mathrm{Yr}$ 


\section{Continuous Monitoring Using Unmanned Aircraft}

For this monitoring option, unmanned aircraft fly over and photograph each silo every 12 hours. We have assumed that uploading missiles requires 12 hours; thus, continuous monitoring requires that each silo be inspected every 12 hours. Since there are 154 missiles, 112,420 inspections must be conducted each year. Two unmanned aircraft teams are required to conduct this number of inspections. The cost of conducting these inspections is the same as that shown in Appendix E, Table E10 for 2 teams.

\section{Cost for continuous monitoring using unmanned aircraft $=\$ 8956 \mathrm{k} / \mathrm{Yr}$}

\section{Continuous Remote Monitoring using Unattended Sensors}

This monitoring option uses unattended sensors that communicate through a satellite up-link to confirm that silo doors have not been opened. The following cost estimate is based on applying a remotely monitored sensor package complete with anti-tampering, data acquisition, and communications hardware to a silo door. Costs are based on estimates provided by Corbell (1998) and are shown in Table F2. He estimates that an engineered monitoring system will cost roughly $\$ 22,000$ per silo: $\$ 5000$ for a sensor package containing multiple sensors including sensors used to help detect tampering, $\$ 7000$ for data acquisition, $\$ 4000$ for on-site communications, $\$ 1000$ for a power supply, and $\$ 5000$ for a secure container. Corbell also estimates that a three-man team can install and check out the system for one silo each day. Site modification costs can be extremely variable depending on the modifications required to attach sensors and on the availability of power. We assumed that site modifications will cost $\$ 5000$ per silo, but this figure is extremely variable.

In addition, we assume that a team must return to each silo once a year to inspect the monitoring system, confirm that it has not been tampered with, and perform necessary maintenance. We assumed that a 3-man team can service 3 silos each day. 
Table F2. Remote Unattended Monitoring System Costs (Present Technology)

Development

$\frac{\$ \mathrm{k}}{320} \quad \$ \mathrm{k} / \mathrm{Yr}$

Sensor system

sensor packaging \& electronics (\$5000 ea x 154) 770

data acquisition (\$7000 ea) 1078

on-site comm ( $\$ 4000$ ea) $\quad 616$

power supply (\$1000 ea) $\quad$. 154

enclosure (\$5000 ea) $\quad 770$

Equipment shipping ( $10 \%$ of sensor system cost) 339

Support engineering ( $\$ 30,000$ first $+\$ 5000$ ea) $\quad 800$

Site Modification $154 @ \$ 5000 \quad 770$

3 man installation team, 154 silos at 1 per day

salaries 336

international travel (1 trip per man every 2 weeks) 55

living expenses 111

local transportation $\quad 15$

training $(\$ 50,000) \quad 50$

2 man escort team

salaries 224

living expenses $\quad 74$

$\begin{array}{ll}\text { Receiver } & 150\end{array}$

Total initial cost 6632

$6632 \$ \mathrm{k}$ amortized over 4 years at $5 \%(.282$ annualization factor $) \quad 1870$

$6632 \$ \mathrm{k}$ amortized over 10 years at 5\% (.130 annualization factor) 862

$\begin{array}{ll}\text { Telephone data relay service } & 30\end{array}$

Data analysis ( 0.5 man years) $\quad 80$

Total system cost amortized over 4 years $\quad 1980$

Total system cost amortized over 10 years 972

Table F3. Remote Unattended Monitoring Costs

Annualized system cost (4 year case)

$\$ \mathrm{k} / \mathrm{Yr}$

1980

Annual inspection and maintenance--3 man team doing 3 silos per day

salaries

international travel (1 trip per man every 2 weeks) 19

living expenses

local transportation

Annual inspection and maintenance--2 man escort

salaries

75

living expenses $\quad 25$

Management

1352

Total annualized cost at 4 years amortization 


\section{APPENDIX G. \\ Design Features for a Monitoring System Using \\ Over-Flights with Unmanned Aircraft}

\section{UAV Characteristics}

Present UAVs (unmanned aerial vehicles) exhibit a wide range of characteristics, ranging from very small, hand-held systems to long endurance systems the size of jet fighters. For the purpose of this analysis we chose the General Atomics high endurance Predator system. This system has been produced in the highest quantities to date of any high endurance UAV system. A picture is shown in Figure G1. Characteristics of these system are shown in Table G1.

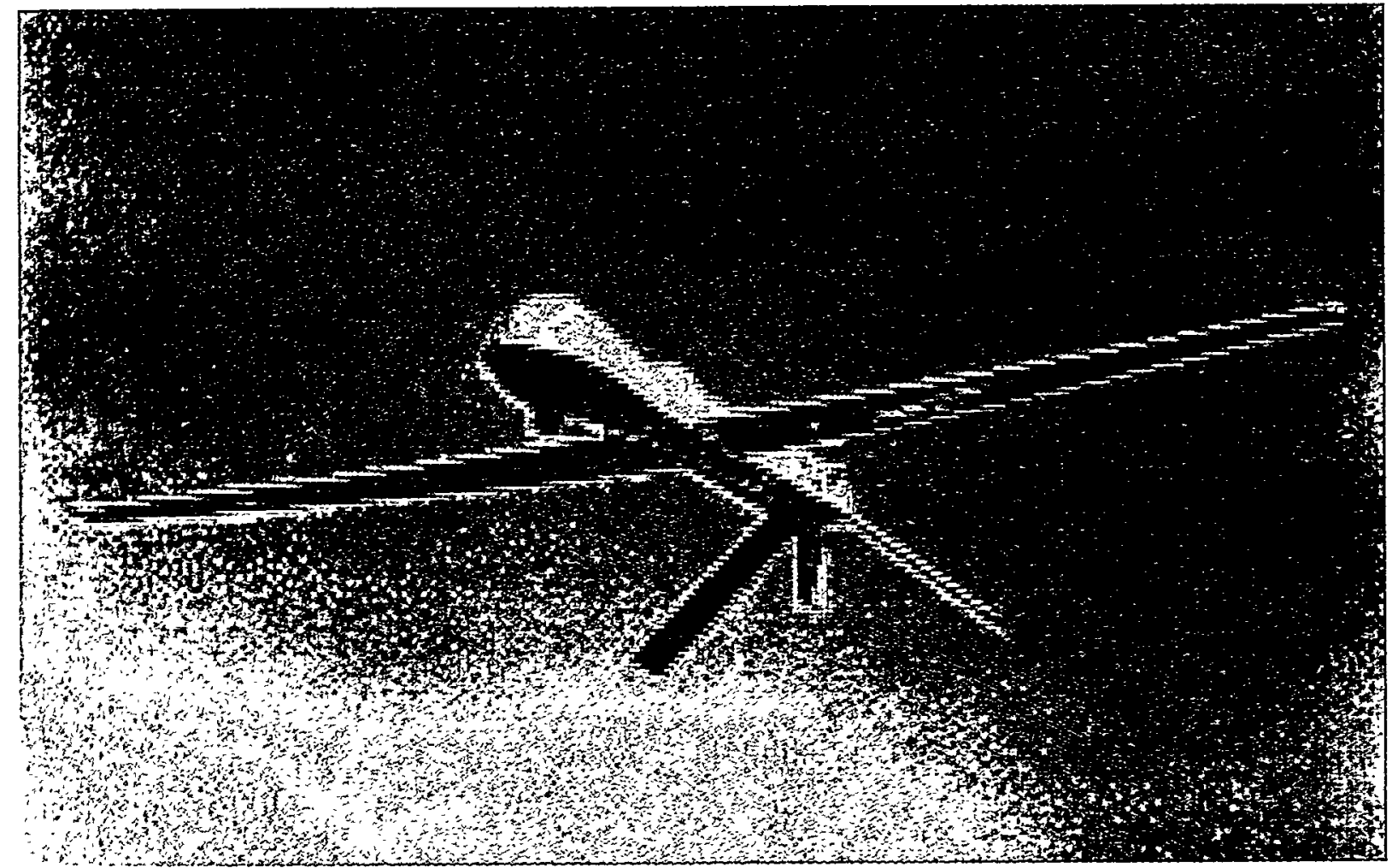

Figure G1. Predator Unmanned Aircraft

A UAV system consists of one or more air vehicles, a ground control station (GCS), and auxiliary equipment such a launcher. The costs cited in this study are for a complete UAV system with one air vehicle. 
Table G1. Predator UAV Characteristics

\begin{tabular}{|c|c|}
\hline Max Alt. (m) & 7600 \\
\hline Endurance (hrs) & Up to 40 \\
\hline Operation Radius (km) & 926 \\
\hline Cruise Speed (km/hr) & 204 \\
\hline Propulsion type & Piston propellor \\
\hline MTOW (kg) & 851 \\
\hline Payload weight (kg) & 204 \\
\hline Wingspan (m) & 14.8 \\
\hline Length (m) & 8.1 \\
\hline Sensor types & EO and IR or SAR \\
\hline Control type & $\begin{array}{c}\text { Direct or satellite data link, } \\
\text { autonomous }\end{array}$ \\
\hline
\end{tabular}

Several sensors are available for installation on UAVs of this size. A typical EO/IR sensor suite is represented by the Versatron Skyball, which combines a daylight TV camera and a 3-5 micron IR imager. A picture of a Skyball is shown in Figure G3, and a picture of a large format aerial camera is shown in Figure G2.

An examination of weather data from the International Station Meteorological Climate Summary data base indicated that the regions of Russia where the silos are located experience a significant amount of cloud cover during the winter months. Reports from stations in the general vicinity of Kartaly and Dombarovsky, the western fields, indicate that overcast conditions prevail from 40 to 60 percent of the time during the November-January time frame. There are fewer stations close to Aleysk and Uzhur, but available data indicates overcast conditions up to 60 percent of the time during the winter months, as well. As reloading campaigns could be timed to coincide with periods of cloud cover, this would indicate that the use of optical sensors may not be a robust choice if large numbers of random inspections were needed. 

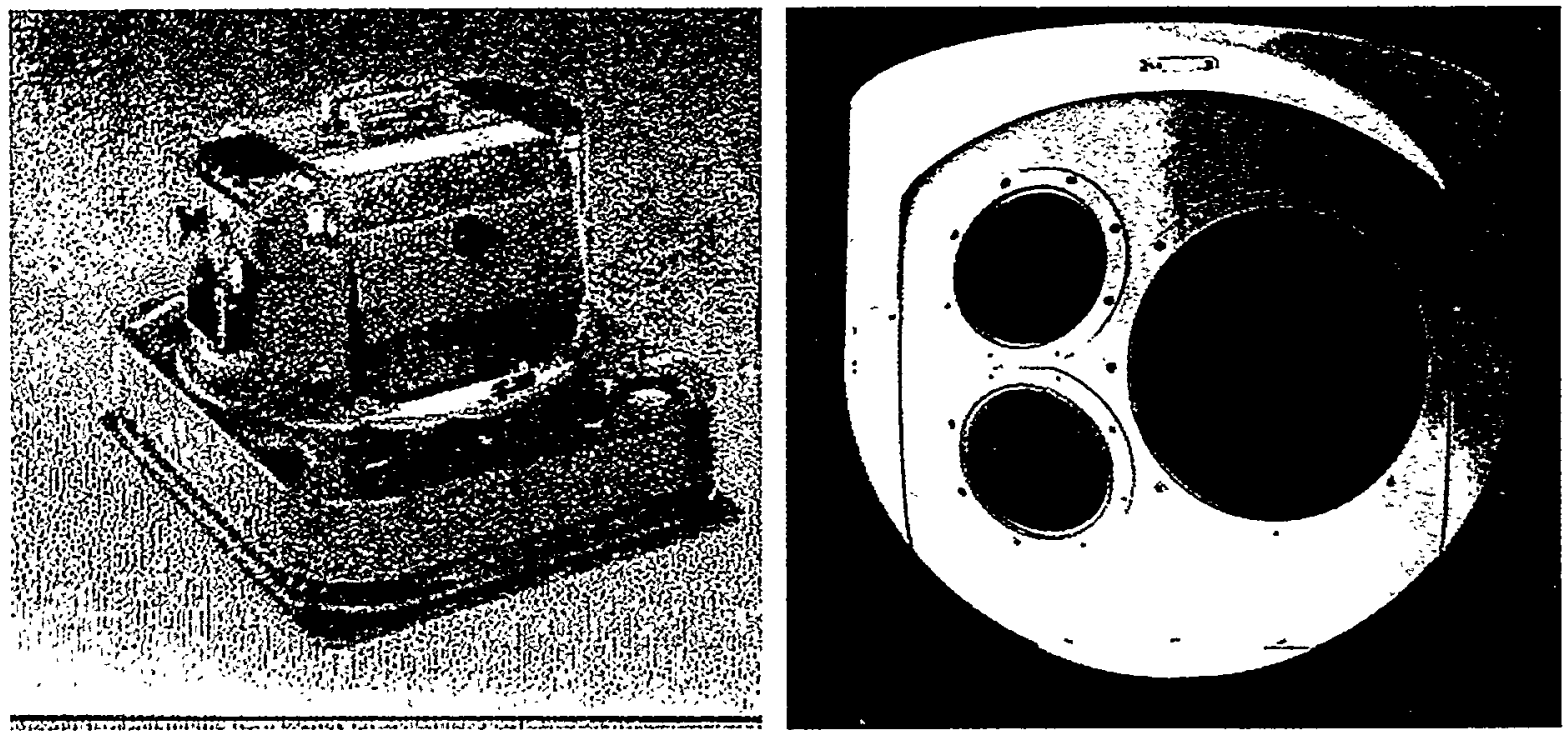

Figure G2. Wilde Large format Camera

Figure G3. Versatron Skyball Sensor Turret

\section{Issues}

Besides the cost and effectiveness issues discussed in the body of this report, there are a variety of other very important issues that will determine the desirability of monitoring using random inspections with a manned or unmanned aircraft system. Some of them are listed here.

- Inspection teams do not require access to the missile silo and do not have to depend on escorts to open gates and silo doors after the initial confirmation is made.

- Inspectors need not live on missile bases; living in close proximity is adequate.

- Permission and flight plans for a large number of inspections may be required. This may interfere with inspection randomness.

- Inspection teams must be based in the host country near missile bases at all times.

- The host country may be concerned about "extra" data gathered by the aircraft.

- Weather may interfere with inspections. Some sensors may not work if there is a cloud cover, and the aircraft may not be able to fly in some weather conditions. 


\section{APPENDIX H. Design Features for a Monitoring System Using Random Monitoring with Silo Door Sensors}

If silo-based missiles are deactivated by removing their warheads, the silo door must be opened to reactivate the missiles by replacing their warheads. A sensor package that confirms that the door has remained closed can be used to monitor deactivation. The sensor package must be capable of detecting when the door is opened as well as detecting its own state of health and attempts to tamper with it, and it must be able to store the associated data. It must also be capable of continuing operation after the door has been opened and reclosed for missile maintenance. Inspectors will randomly inspect and interrogate the sensor package to obtain its data. They will also replace a few sample packages and subject them to a thorough tamper identifying analysis.

We collaborated with Bob Corbell of Sandia's Security Systems and Technology Center and Fred Mendenhall of Sandia's Systems Assessment and Research Center to develop some conceptual sensor package ideas for monitoring a missile silo door. A variety of sensor options are available including video cameras, magnetic switches, fiberoptic sensors, bistatic break beams, inclinometers, and accelerometers. One design that looks promising is a two part sensor package using a magnetic Hall-effect switch and a bistatic break beam. One part is mounted to the door, and the other is mounted next to it on the flange that the door seats into. Figure G1 shows a conceptual design for this option.

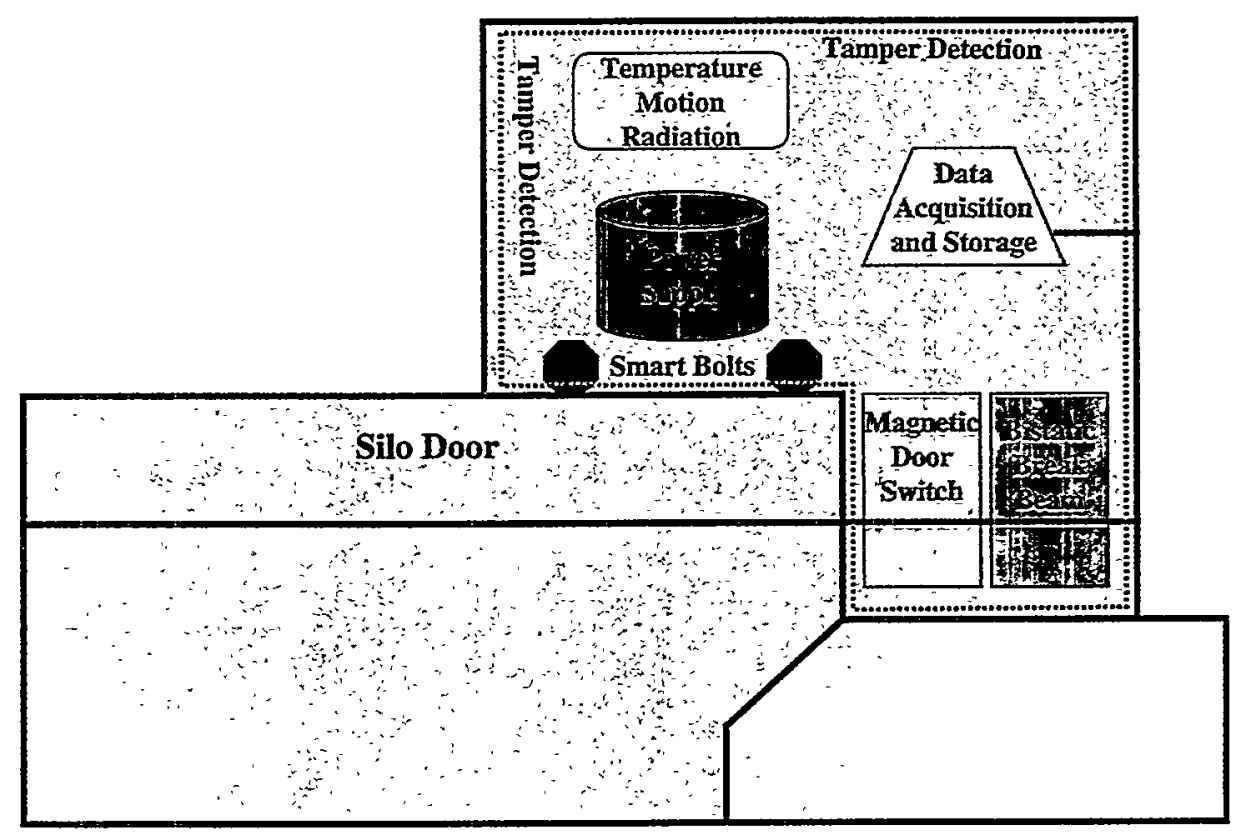

Figure H1. Conceptual Design for a Silo Door Sensor 
Using the two independent sensors (magnetic switch and bistatic break beam) will reduce the number of false alarms. In addition, the sensor package would contain sensors such as a temperature sensor, smart bolts, and maybe an accelerometer to help detect tampering attempts. Also, the sensor package would contain a power supply, data acquisition and authentication circuitry, and small computer to store data. Both parts of the sensor package would be enclosed by containers that incorporate tamper resistant elements. Data from the sensors would be stored on site and retrieved and analyzed by inspectors during inspections. We imagine that an inspector would carry a portable computer (laptop) containing software that stores and analyzes the data and displays the results in an easily interpretable format.

We considered more conventional passive sensors for this application but did not recommend them because we are concerned about their vulnerability to tampering.

\section{Issues}

- Silo doors need not be opened (except for the initial confirmation) for an inspection; however, inspectors must get frequent access to silo doors.

- There is a potential vulnerability to tampering because the host country has access to the sensor package during the time between inspections. Random RV-OSIs may be necessary if there is suspicion of tampering.

- Sensors and other system components may be vulnerable to the environment.

- While individual monitoring devices are technologically mature, their application in an integrated system to a silo door is new and unproven.

- The host country could implement a program to degrade confidence in the sensors.

- The sensors may produce false alarms.

- The sensors and monitoring regime must deal with door openings for missile service. 


\section{APPENDIX I. \\ Design Features for a Continuous Remote Monitoring System Using Unattended Door Sensors}

This monitoring system is similar to the one that uses random inspections with door sensors described in Appendix H. Continuous (or frequent) communication with the sensor package is used, instead of random inspections, to confirm that the silo door has not been opened which assures that warheads have not been replaced. The sensor package design would be the same as that described in Appendix $\mathrm{H}$ with the addition of a satellite up-link for two-way telecommunications and a ground station at a central site where data is received, stored, and analyzed with automated data processing software.

To reduce the possibility of undiscovered tampering, we suggest that each silo would be visited each year for sensor package maintenance and inspection. A few randomly selected sensor packages would be replaced and returned for detailed analysis.

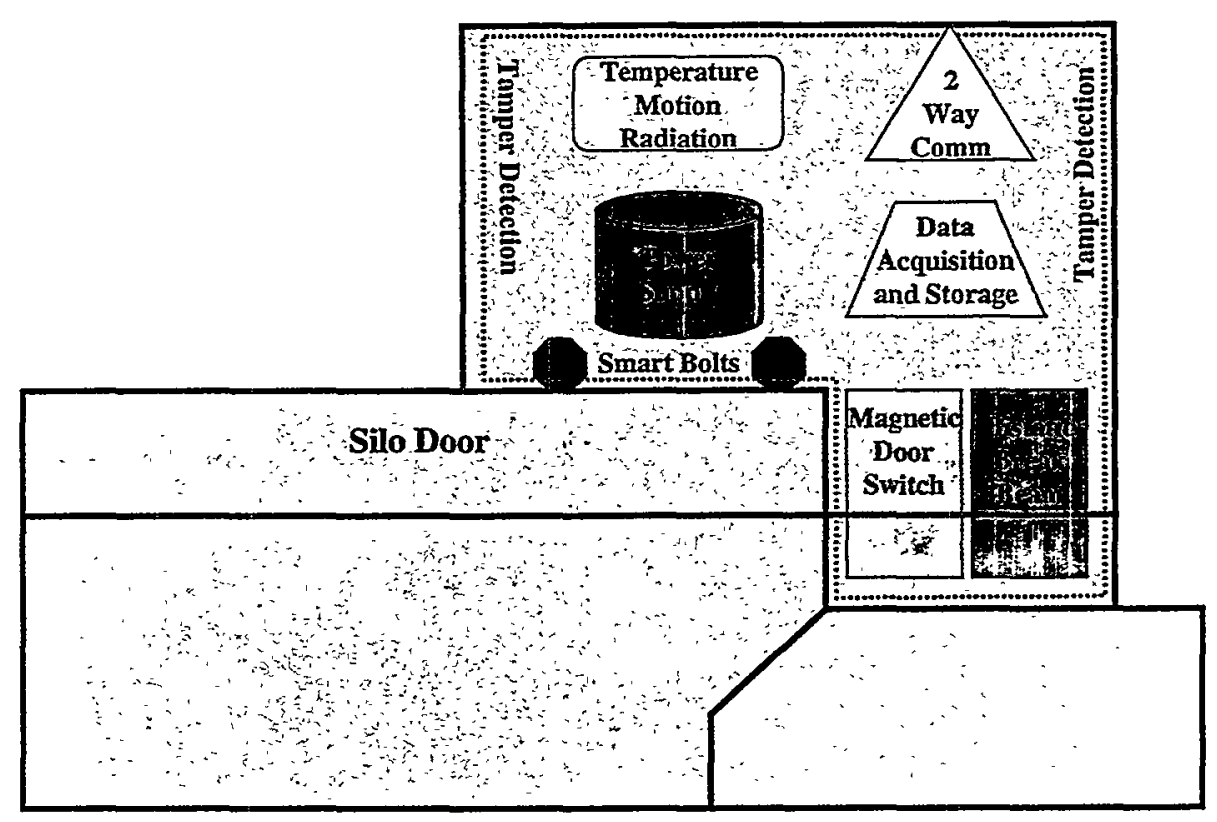

Figure 11. Conceptual Design for an Unattended Silo Door Sensor 


\section{Issues}

- Silo doors need not be opened for an inspection (except for the initial confirmation), and inspectors do not need access to silo doors or the missile sites except for annual maintenance.

- There is a potential vulnerability to tampering because the host country has access to the sensor package. Tampering may be relatively difficult because the sensor package is communicating frequently.

- Sensors and other system components may be vulnerable to the environment.

- While individual monitoring devices use mature technology, their integrated application to a silo door is new and unproven.

- The host country could implement a program to degrade confidence in the sensors.

- The sensors may produce false alarms.

- The sensors and monitoring regime must deal with door openings for missile service.

- The host country may object to radio transmissions from the silo site. 


\section{REFERENCES}

Air Force 1989: Department of the Air Force, US Air Force Cost and Planning Factors, AF Regulation 173-13, 1989.

Bradley, 1998: Jeff Bradley, Sandia National Laboratories Advanced Sensors and navigation Dept. 2424 Personal communication, December 1998.

Bolton, 1998: Will Bolton, Sandia National Laboratories Exploratory Systems Dept. 8120, Personal Communication 12/07/98.

Brock, 1998: Brian Brock, Sandia National Laboratories Satellite System Engineering Dept. 5711, Personal Communication, November 1998.

Budge, 1998: Tom Budge, Earth Data Analysis Center, University of New Mexico, Personal Communication, October 1998.

Corbell 1998: Bob Corbell, Sandia National Laboratories Cooperative Monitoring Systems Dept. 5825, Personal Communication, 8/27/98.

Ginsberg, 1998: Bill Ginsberg, Remote Sensing Laboratory, Personal Communication, November, 1998

Jane's, 1998: Jane's Strategic Weapons Systems, 1998.

Leahy, 1998: Jim Leahy, OSIA, Personal Communication, 10/6/98.

Reporter, 1998: The Arms Control Reporter, December, 1998.

Skipper, 1998: Anna Skipper, OSIA, Personal Communication, 10/6/98.

Wu, 1999: Sherman Wu, Remote Sensing Laboratory, Personal Communication, January, 1999. 


\section{Distribution:}

$1 \quad$ U.S. Department of Energy 1000 Independence NW Washington, DC 20585 Bob Waldron NN/20 MS-GH068

3 U.S. Department of State $32021^{\text {st }}$ Street NW Washington, DC 20451 O. J. Sheaks T/SAVC Karin Look AC Sarah Mullen AC/TA

1 U.S. Defense Threat Reduction Agency 45045 Aviation Drive Dulles, VA 20166-7517 Jim Leahy /OSF

1 HQ USSTRATCOM/J5B/J51

901 SAC Blvd. Ste. 2E10

Offutt AFB, NE 68113-6500 Dr. Hardebeck

1 HQ USSTRATCOM/J030

901 SAC Blvd. Ste. 1F7

Offutt AFB, NE 68113-6030

Capt. Sediby

1 MS $0764 \quad$ Bob Corbell, 5315

1 MS 1215 Rich Preston, 5336

1 MS 1215 Bob Gough,5336

1 MS 1203 Dennis Croessmann, 5337

1 MS 1203 Bob Huelskamp, 5337

1 MS 1371 George Baldwin, 5338

1 MS 1371 Dave Barber, 5338

1 MS 1373 Kent Biringer, 5341

1 MS 1373 Arian Pregenzer, 5341

1 MS $1131 \quad$ Lyle Kruse, 5849

1 MS 1219 John Taylor, 5907

1 MS 1206 Sid Gutierrez, 5932

1 MS 0839 Tom Karas, 16000

1 MS 1205 Dave Nokes, 5900

1 MS1204 Fred Mendenhall, 5902 


$\begin{array}{lll}1 & \text { MS 1201 } & \text { Ron Moya, 5908 } \\ 1 & \text { MS 0151 } & \text { Tom Hunter, 9000 } \\ 1 & \text { MS 0469 } & \text { Ron Detry, 9800 } \\ 1 & \text { MS 0421 } & \text { Curtis Hines, 9801 } \\ 1 & \text { MS 0415 } & \text { Keith Almquist, 9811 } \\ 1 & \text { MS 0417 } & \text { Bill Ling, 9813 } \\ 1 & \text { MS 0417 } & \text { Steve Hatch, 9813 } \\ 1 & \text { MS 0417 } & \text { Mitch Slate, 9813 } \\ 1 & \text { MS 0421 } & \text { Janet Sjulin, 9814 } \\ 1 & \text { MS 0421 } & \text { John Arfman, 9814 } \\ 1 & \text { MS 0425 } & \text { Stan Fraley, 9815 } \\ 1 & \text { MS0425 } & \text { Len Connell, 9815 } \\ 20 & \text { MS 0425 } & \text { Mike Edenburn, 9815 } \\ 10 & \text { MS 0425 } & \text { Larry Trost, 9815 } \\ 1 & \text { MS 0423 } & \text { Bob Paulsen, 9817 } \\ 2 & \text { MS 0889 } & \text { Technical Library,4916 } \\ 1 & \text { MS 0612 } & \text { Review and Approval, 4912 } \\ & & \text { for DOE/OSTI } \\ 1 & \text { MS 9015 } & \text { Central Technical Files, 8940-2 }\end{array}$

